\title{
Supercritical solvothermal synthesis under reducing conditions to increase stability and durability of Mo/ZSM-5 catalysts in methane dehydroaromatization
}

Ignacio Julian ${ }^{a, b,}{ }^{*}$, Morten B. Roedern ${ }^{d}$, Jose L. Hueso ${ }^{a, b, c}$, Silvia Irusta ${ }^{a, b, c}$, Ane K. Baden $^{d}$, Reyes Mallada ${ }^{a, b, c}, Z^{2}$ achary Davis ${ }^{d}$, Jesus Santamaria ${ }^{a, b, c, *}$

anstitute of Nanocience of Aragon (INA) and Department of Chemical and Environmental Engineering (IQTMA), University of Zaragoza, 50018 Zaragoza, Spain

${ }^{b}$ Instituto de Ciencia de Materiales de Aragon (ICMA), Consejo Superior de Investigaciones Científicas (CSIC-Universidad de Zaragoza), 50009, Zaragoza, Spain

${ }^{c}$ Networking Research Centre CIBER-BBN, 28029 Madrid, Spain

${ }^{d}$ Centre Nano Production and Micro Analysis, Danish Technological Institute, DK-2630 Taastrup, Denmark

*Corresponding authors: ijulian@unizar.es; jesus.santamaria@unizar.es

\section{ABSTRACT}

Natural gas is currently envisioned as a potential energy and hydrocarbon feedstock in the forthcoming years. To overcome the detrimental flaring of this natural gas and the partial release of its major component, methane, novel and more effective strategies are required. These include the development of new, efficient and seemingly stable catalysts able to rapidly convert methane into valuable feedstocks. We show a novel synthesis method of Mo/ZSM-5 based on a solvothermal synthesis under supercritical 
conditions and reducing atmosphere (SC-STS-E) to improve metal dispersion and enhance catalyst stability and durability during the methane dehydroaromatization (MDA) reaction. In contrast to the conventional impregnation method, SC-STS-E provides a super-high atom-like metal dispersion at the zeolite pores resulting in the most stable Mo/ZSM-5 catalyst for MDA with the highest long-term hydrocarbon yield $\left(\mathrm{x}_{\mathrm{CH} 4}=11.6 \%\right.$ and $\mathrm{y}_{\mathrm{C} 2+}=8.9 \%$, after $15 \mathrm{~h}$ on stream $)$ among the catalysts reported in literature for this reaction.

\section{Keywords}

Methane dehydroaromatization, Mo/ZSM-5, metal dispersion, supercritical solvothermal synthesis, benzene production

\section{INTRODUCTION}

Natural gas and its major component, methane $\left(\mathrm{CH}_{4}\right)$ have emerged in recent years as the most appealing source of energy and hydrocarbons to fulfil worldwide increasing energy demands [1-3]. Natural gas abundance, depletion of fossil fuels and the absence of mature sustainable and environmentally friendly alternatives appear as key factors to explain the recent flourish of shale gas exploitation as transitional technology for forthcoming years. The enormous reserves found (proven world natural gas reserves were 193.5 trillion cubic meters for the year 2017 [4], plus $10^{15}$ to $10^{18} \mathrm{~m}^{3}$ of methane stored in hydrates [5]), environmental sustainability and lower overall costs point to natural gas as the primary source for energy and chemicals in the near future. In addition to the well-planned and growing-in-number off-shore gas terminals, several exploration sites can operate economically, but have a severe problem of being 
dislocated from the main grid veins. For this reason, the great variety of the methane sources, including existing gas networks, small natural gas fields, shale, coal beds, agricultural biogas and deep-sea methane hydrates creates an urgent need to develop catalytic reactor systems able to activate methane and rapidly transform it into longer hydrocarbons fractions or liquid fuels that can be more easily driven to the potential end-users [1, 3]. A rapid and efficient transformation will be essential to ensure the economical viability of the process while minimizing current undesired flaring and uncontrolled release of methane, a well-known greenhouse gas, during the extraction process $[1,6,7]$

Likewise, the search for novel and more stable catalysts has been reactivated in the past few years. In particular, in the last decades a tremendous effort has been done to develop catalysts to carry out the challenging one-step, non-oxidative conversion of natural gas into valuable chemicals via methane dehydroaromatization (MDA) [8-11]. In contrast to oxidative and other indirect routes, the direct non-oxidative coupling of methane is potentially more economical and environmentally friendly despite its thermodynamic limitations [2]. It is widely accepted that catalysts based on Mo as active metal supported on zeolites (ZSM-5) or zeotypes (MCM-22) are able to perform a partial conversion of methane into aromatics (mainly benzene and naphthalene) and $C_{2}$ species $[8,11]$. Although the technology is promising, it has not been implemented yet at industrial scale due to a number of process limitations. The catalytic conversion of methane on Mo/ZSM-5 starts to be noticeable (> 5\%) at temperatures around $650^{\circ} \mathrm{C}$ or above. However, these temperatures strongly promote the chemical dehydrogenation of methane into $\mathrm{H}_{2}$ and highly dehydrogenated carbon deposits (coke) of limited or no added value. As a result of coking, the catalyst suffers from 
severe deactivation along the time on stream, thus, leading to unsteady operation with low yield to the products of interest $\left(\mathrm{Y}_{\mathrm{C} 6 \mathrm{H} 6}<6 \%\right.$ after some hours on stream) $[3,9,12]$. With these limitations, the standard operation conditions to maximize aromatics production and prevent catalyst deactivation are: spatial velocities in the range of $1400-1600 \mathrm{~mL} / \mathrm{g}_{\mathrm{cat}} \mathrm{h}$, reaction temperature of $700^{\circ} \mathrm{C}$, atmospheric working pressure, molybdenum loading between $3-6$ wt.\% and ZSM-5 zeolite acidity, i.e. Si/Al ratio, comprised between 15 and $40[9,10,13]$. Under these reaction conditions, the transient methane conversions and aromatics selectivities are typically in the range 10 $-12 \%$ and $60-80 \%$, respectively [12]. Nonetheless, recent reports show that MDA would be similarly effective in a broader range of space velocities and that working at elevated pressures has apparently a very positive effect on the reaction [14].

In the recent years, an extensive effort has been devoted to understand both the nature of the active species of this catalyst and the reaction mechanism in order to enhance the performance and durability of the employed materials $[12,15-20]$. It is accepted that the formation of large $\mathrm{MoO}_{\mathrm{x}}$ aggregates or Mo clusters onto the zeolite surface is detrimental due to fast coke formation and rapid catalyst deactivation. In contrast, a good dispersion of Mo active entities within the zeolite channels may retard and somehow inhibit coke deposition on the active sites as well as pore blocking $[3,12,21-23]$. Typically, the impregnation of the zeolite with a Mo precursor $\left(\mathrm{MoO}_{3}\right.$ or $\left.\left(\mathrm{NH}_{4}\right)_{6} \mathrm{Mo}_{7} \mathrm{O}_{24} \cdot 4 \mathrm{H}_{2} \mathrm{O}\right)$ is followed by drying and calcination at $500-550^{\circ} \mathrm{C}$ to promote the migration of $\mathrm{MoO}_{\mathrm{x}}$ species inside the zeolite micropores. These experimental conditions using controlled temperature ramps are able to provide a reasonably good metal dispersion [12]. Nevertheless, the fine control of this dispersion is rather limited. 
In an attempt to enhance the catalyst activity, reduce coking and extend its stability, in the present work we propose a novel synthesis route for the benchmarking Mo/ZSM-5 catalyst based on the solvothermal incorporation of Mo to the zeolite under supercritical conditions [24, 25]. It consists on the intimate mixing of Mo and zeolite precursors in the presence of a solvent under supercritical conditions. The mixture behaves as a hybrid matter state transitioning between a liquid and a gas, i.e. the supercritical fluid can effuse through solids like a gas and dissolve materials like a liquid. To the best of our knowledge, this solvothermal synthesis under supercritical conditions has not been reported before to prepare MDA catalysts. Taking advantage of the supercritical fluid properties, we aimed at enhancing the metal dispersion within the zeolite channels in order to increase the number of active sites, improve the reaction rates, reduce coke deposition and, thus, delay catalyst deactivation. Furthermore, the presence of an additional alcohol (i.e. ethanol) as reducing agent has been successfully tested as a positive factor to promote the stability of the Mo/ZSM-5 catalyst during the MDA reaction.

\section{EXPERIMENTAL}

\subsection{Catalyst preparation}

For the sake of comparison, the developed Mo/ZSM-5 based catalysts were synthesized using either a conventional incipient wetness impregnation method (IMP) or under supercritical solvothermal conditions (hereafter referred as SC-STS). The latter method implied the use of a self-built reactor setup described elsewhere [24, 25] and depicted in Figure 1. Briefly, a continuous flow of cold Mo precursor solution and 
the zeolitic support (H-ZSM-5) is mixed with a hot solvent (water-ethanol mixture) inside the reactor. Upon mixing under supercritical conditions for the solvent phase, a super-fast precipitation of highly dispersed metal precursor nanoparticles occurs onto the support material.

The precursor and solvent are pumped into the reactor with the aid of membrane pumps, while the flow is monitored by rotameters. A pressure relief valve is used to control the pressure inside the reactor. The solvent is heated to a specified temperature before it is mixed with the precursor in a simple T-piece mixing joint from where the sample is led into the temperature controlled vertical section of the reactor. After the heated section of the reactor, the product solution is cooled to room temperature by water and finally collected. The temperature is monitored in the mixing points and after the cooler.

The supercritical solvothermal synthesis was carried out either in the presence (SCSTS-E) or absence (SC-STS) of ethanol in the solvent phase. In the case of the SC-STS samples, pure water was used as supercritical solvent. For SC-STS-E samples, supercritical $10 \% \mathrm{v} / \mathrm{v}$ ethanol solution in water was employed. The catalyst precursor solution containing the Mo precursor and dispersing agents was prepared by dissolving the soluble species in a $60 \% / 40 \% \mathrm{v} / \mathrm{v}$ ethanol/water mixture followed by the addition of the solid support material. Specifically, the employed materials were: molybdenum acetylacetonate (Mo(acac), 99.9 \%, Sigma Aldrich), PVP4OK (99.99 \%, Sigma Aldrich), BYK7410ET (BYK) or Dolapix CE64 (Zschimmer \& Schwarz) as dispersing agents and zeolite support, $\mathrm{NH}_{4}$-ZSM-5 Zeolyst CBV2314, being the silica-to-alumina (SAR) ratio of 23. The zeolite supports were ball-milled prior to the supercritical STS step. The 
presence of ethanol in the catalytic precursor solution was required to dissolve the Mo(acac) precursor. Furthermore, the addition of ethanol within the supercritical solvent phase was aimed to create a reducing atmosphere in order to change the oxidation state of Mo precursor. Under supercritical conditions, ethanol decomposes into $\mathrm{H}_{2} / \mathrm{CO} / \mathrm{CO}_{2}[26]$, which are able to reduce Mo (VI) species to Mo (IV). The theoretical target loading of Mo on ZSM-5 was 5 wt.\% in all cases. The precursor solution was kept under constant stirring at all times.

In every preparation, the solvent was pre-heated up to $450{ }^{\circ} \mathrm{C}$. The temperature of the vertical section in the reactor was set to $400{ }^{\circ} \mathrm{C}$ and the pressure was adjusted to 220 bar to ensure supercritical conditions for the solvent phase (see Figure 1b). The initial and latest fractions of collected product were systematically discarded. The product suspension was centrifuged at 10,000 rpm for $5 \mathrm{~min}$ in $200 \mathrm{~mL}$ canisters. The product was rinsed with absolute ethanol and dried at room temperature for $24 \mathrm{~h}$. As stated above, the sample prepared using pure water as supercritical solvent was denoted as 'SC-STS' whereas the sample prepared with a mixture of water and ethanol as reducing agent in the supercritical solvent phase was labelled as 'SC-STS-E'. As a final step, the samples were calcined in air for $6 \mathrm{~h}$ at $550^{\circ} \mathrm{C}$ leading to the re-oxidation of the previously reduced Mo species in case of the SC-STS-E sample.

For the preparation of the catalyst by the standard impregnation method (IMP), the same theoretical metal loading (5\%wt. Mo) and zeolite support (CBV2314, $\mathrm{SiO}_{2} / \mathrm{Al}_{2} \mathrm{O}_{3}=$ 23, from Zeolyst) were employed. An aqueous solution of ammonium heptamolybdate tetrahydrate, $\left(\mathrm{NH}_{4}\right)_{6} \mathrm{Mo}_{7} \mathrm{O}_{24} \cdot 4 \mathrm{H}_{2} \mathrm{O}$ (Merck), was poured dropwise on a zeolite powder sample until incipient wetness condition under manual stirring. The impregnated 
sample was dried at $120^{\circ} \mathrm{C}$ and calcined at $550^{\circ} \mathrm{C}$ (heating ramp: $1^{\circ} \mathrm{C} / \mathrm{min}$ ) for 6 hours. The resulting Mo/ZSM-5 catalyst was denoted as 'IMP'.

Figure $1 \mathrm{c}$ and $1 \mathrm{~d}$ show a schematic representation of both synthesis procedures. In the SC-STS and SC-STS-E methods, the metal precursor dissolved in the supercritical fluid mixing was intimately mixed with the loosely suspended zeolite particles along the reactor tube. On the other hand, in case of IMP, an aqueous solution of metal precursor was poured dropwise on bulk zeolite aggregates under stirring, aiming at its diffusion through the pores of the support by capillarity [27].

The syntheses of the nanomaterials have been performed by the Platform of Production of Biomaterials and Nanoparticles of the NANOBIOSIS ICTS, more specifically by the Nanoparticle Synthesis Unit of the CIBER in BioEngineering, Biomaterials \& Nanomedicine (CIBER-BBN).
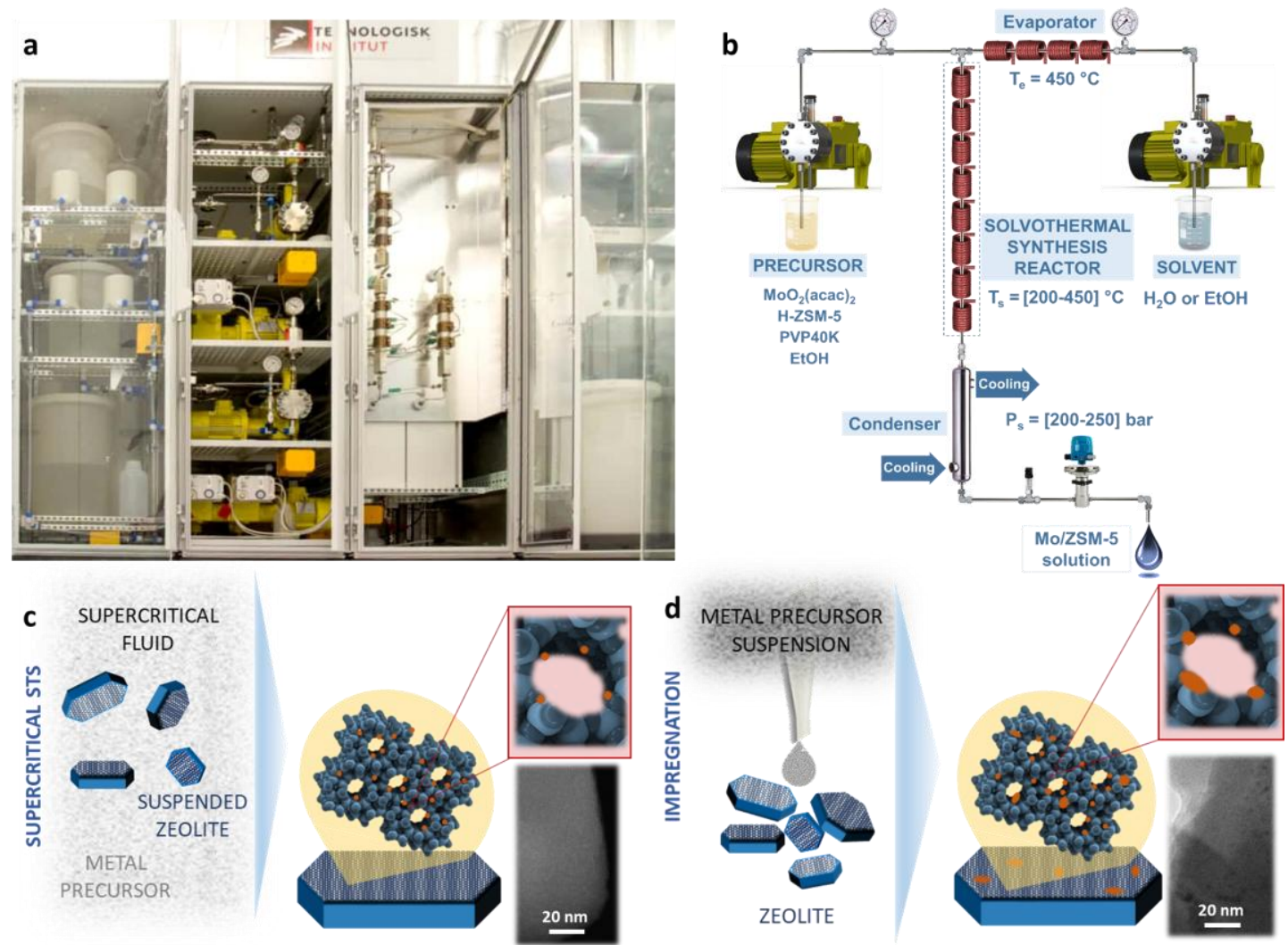

VERY WELL-DISPERSED MO ATOMS AT THE ZSM-5 PORES

WELL-DISPERSED MO CLUSTERS AT THE ZSM-5 PORES 
Figure 1. Schematic overview of the synthesis approaches described in this work: a) Digital photograph of the supercritical setup; b) Simplified scheme of the reaction conditions to carry out the supercritical synthesis; c) Sketch of the supercritical conditions and the obtained catalyst, including a representative HAADF-STEM image accounting for the excellent Mo dispersion; d) Schematic overview of the impregnation method including a STEM image to illustrate the formation of some non-internalized aggregates.

\subsection{Catalyst characterization}

The synthesized catalysts were thoroughly characterized by a number of techniques: Raman spectroscopy, Argon adsorption, Thermogravimetric analysis (TGA), Scanning and Scanning-Transmission Electron Microscopy (SEM, STEM) with Energy-Dispersive X-ray spectroscopy (EDX), X-ray photoelectron spectroscopy (XPS), X-ray diffraction (XRD), Temperature-programmed desorption of ammonia $\left(\mathrm{NH}_{3}-\mathrm{TPD}\right),{ }^{27} \mathrm{Al}$ magic angle spinning nuclear magnetic resonance $\left({ }^{27} \mathrm{Al}\right.$ MAS NMR) as well as Fourier-Transform Infrared spectroscopy of CO adsorption (CO-FTIR). Raman spectroscopy measurements were performed with an Alpha 300 Raman spectrometer (WITec) using a $532 \mathrm{~nm}$ laser source and CCD camera as detector to identify the presence and coordination of Mo species in the catalytic samples. The selected laser power and integration time were 8 $\mathrm{mW}$ and $2 \mathrm{~s}$, respectively. Argon adsorption was employed to study the textural properties of the catalysts, evaluating the adsorption isotherm. The specific surface area was calculated by BET equation, considering consistency criteria proposed by Rouquerol for microporous materials [28] and the micropore volume was evaluated at $P / P_{0}=0.01$. The measurements were carried out using a Micromeritics ASAP 2020 analyzer. Samples were degassed at $350^{\circ} \mathrm{C}$ prior to the analysis. TGA and DTG 
(differential TGA) were used to determine changes in the mass that coked catalysts undergo when heated at a programmed temperature under oxidizing atmosphere. A Q5000SA thermal analyser (TA Instruments) was employed. The measurements were carried out in air at a heating rate of $10^{\circ} \mathrm{C} / \mathrm{min}$ from room temperature to $900^{\circ} \mathrm{C}$. TEM (Tecnai F30, FEI) and HAADF Scanning-TEM (Titan Low Base 60-300, FEI) were employed to evaluate the dispersion of Mo species and the eventual formation of aggregates on the zeolite external surface. SEM-EDX was used to evaluate the morphology of the catalysts and Mo distribution on the surface of the zeolite support. The analyses were carried out in a scanning electron microscope INSPECT-F50 from FEI Company. XPS measurements were performed with an Axis Ultra DLD (Kratos Tech.) equipment. The spectra were excited by a monochromatized AlK $\alpha$ source (1486.6 eV) run at $15 \mathrm{kV}$ and $10 \mathrm{~mA}$ to analyse the oxidation state of the Mo species in calcined, coked and regenerated catalytic samples. The binding energies were referenced to the internal C1s (284.6 eV) standard of adventitious carbon. XRD was employed to identify the structural changes of the raw zeolite ZSM- 5 by the addition of molybdenum and by MDA-regeneration cycles. Diffraction data were measured on an Empyrean diffractometer from PANanalytical operating at $45 \mathrm{kV}$ and $40 \mathrm{~mA}$, using CuK $\alpha$ radiation. XRD patterns were collected from $2 \theta=10^{\circ}$ to $50^{\circ}$. $\mathrm{NH}_{3}$-TPD measurements were performed to investigate the acidic properties of the catalysts in an AutoChem II 2920 from Micromeritics using the following procedure: first, $100 \mathrm{mg}$ of the catalytic samples were pretreated in $\mathrm{He}(30 \mathrm{~mL} \mathrm{sTP} / \mathrm{min})$ at $500^{\circ} \mathrm{C}$ for 1 hour to remove the adsorbed water and organic species. After saturating with a $5 \%$ vol. $\mathrm{NH}_{3} / \mathrm{He}$ mixture gas $\left(60 \mathrm{~mL} \mathrm{stp}_{\mathrm{p}} / \mathrm{min}\right)$ at $120^{\circ} \mathrm{C}$ for $60 \mathrm{~min}$, the samples were degassed with He for 1 hour. $\mathrm{NH}_{3}$ was then desorbed in the temperature range $120-600^{\circ} \mathrm{C}$ at a heating ramp of 
$10^{\circ} \mathrm{C} / \mathrm{min}$ under $60 \mathrm{mLSTP} / \mathrm{min}$ He. The desorbed $\mathrm{NH}_{3}$ was monitored by thermal conductivity detector (TCD). ${ }^{27} \mathrm{Al}$ MAS NMR was conducted to evaluate the effect of Mo addition on the change of the zeolite structures. The ${ }^{27} \mathrm{Al}$ MAS NMR spectra were recorded at $104.3 \mathrm{MHz}$ using a $2.5 \mu$ s pulse with a 3 s recycle delay (2048 scans) on a $400 \mathrm{MHz}$ solid-state Bruker Avance AV-400-WB NMR spectrometer using a $4 \mathrm{~mm}$ probe. Samples were spun at $8 \mathrm{kHz}$. FTIR of adsorbed CO was performed to analyse the Brønsted acidity of the catalytic samples prior and after Mo incorporation. The measurements were conducted in a Nexus 8700 FTIR spectrometer with DTGS detector and $4 \mathrm{~cm}^{-1}$ resolution. Self-supported wafers containing the different Mo/ZSM-5 samples $\left(10 \mathrm{mg} / \mathrm{cm}^{2}\right)$ were first pre-treated in oxygen at $400^{\circ} \mathrm{C}$ ( 2 hours) followed by degassing under dynamic vacuum at $300^{\circ} \mathrm{C}$. After cooling the system down to $-120^{\circ} \mathrm{C}$, CO was dosed and adsorbed at increasing pressures (0.1 to $1 \mathrm{mbar}$ ), thus, collecting the resulting IR spectra after each dose.

\subsection{Catalytic testing}

The obtained catalytic powders from both supercritical - solvothermal synthesis (SCSTS) and impregnation (IMP) were tested for methane dehydroaromatization. The experimental set-up and standard operational conditions are shown up next. A fixed bed containing $0.5 \mathrm{~g}$ of $5 \% \mathrm{wt}$. Mo/ZSM- 5 catalyst was placed in a vertical quartz tube located inside an electrical oven. A temperature ramp of $20^{\circ} \mathrm{C} / \mathrm{min}$ was employed to heat the sample up to $700^{\circ} \mathrm{C}$ using a methane-rich gas flow $\left(80 \% \mathrm{CH}_{4}-20 \% \mathrm{~N}_{2}\right)$ in order to keep a reducing atmosphere to carburize $\mathrm{Mo}$ species into $\mathrm{MoC}_{\mathrm{x}} \mathrm{O}_{\mathrm{y}}$ and $\mathrm{Mo}_{2} \mathrm{C}$. Experimental reaction tests were conducted in fixed beds of Mo/ZSM-5 powders (aggregates size: $100-250 \mu \mathrm{m}$; external diameter of the quartz tube: $12 \mathrm{~mm}$ ) at $700^{\circ} \mathrm{C}$ 
using a diluted methane flow $\left(\mathrm{CH}_{4}: \mathrm{N}_{2}=80: 20\right)$ and a spatial velocity of the inlet gas mixture of $1500 \mathrm{~mL}$ STP $/ \mathrm{g}_{\text {cat }} \cdot \mathrm{h}$. Three mass flow controllers (Bronkhorst 0-20 mLSTP/min) were employed to feed either the reactive mixture or the catalyst regeneration flow $\left(\mathrm{N}_{2}: \mathrm{O}_{2}=19: 1,2400 \mathrm{~mL} \mathrm{sTp}_{\mathrm{p}} / \mathrm{g}_{\mathrm{cat}} \cdot \mathrm{h}\right)$. Nitrogen (99.999\% Praxair) was here employed as internal standard for the quantification of the product gas flow, pure methane $199.5 \%$ Praxair) was the gas reactant and oxygen (99.999\% Praxair) was the oxidizing agent. The composition of the outlet gas was analysed with a GC (Thermo Fisher Scientific TRACE1310) equipped with one thermal conductivity detector (TCD) and two flame ionization detectors (FID) for the analysis of permanent gases, light hydrocarbons and aromatics, respectively. The columns employed for the separation of the three groups of outlet gas components were Shincarbon, Plot Alumina and TR-1, respectively.

Methane conversion $\left(\mathrm{x}_{\mathrm{CH} 4}\right)$ and hydrocarbon selectivity $\left(\mathrm{S}_{\mathrm{CxHy}}\right)$ were calculated using Equations 1 and 2 , being $\dot{n}_{\mathrm{i}}, \dot{V}_{i}, \mathrm{~A}_{\mathrm{i}}$ and $\mathrm{RF}_{\mathrm{i}}$ the molar flow, volumetric flow, peak area and response factor of the species i, respectively. The response factor represents the ratio between the response of a detector to a compound (peak area) and the concentration of that compound in a mixture of gases. The hydrocarbon yield $\left(\mathrm{Y}_{\mathrm{CxHy}}\right)$ is defined as the product of conversion by selectivity $[29,30]$.

$$
\begin{aligned}
& x_{C H_{4}}=\frac{\dot{n}_{C H_{4, \text { in }}}-\dot{n}_{C H_{4, \text { out }}}}{\dot{n}_{C H_{4, \text { in }}}}=\frac{\dot{V}_{C H_{4, \text { in }}}-\frac{{ }_{C H_{4, \text { out }}} / R F_{C H_{4}}}{A_{N_{2, \text { out }} / R F_{N_{2}}}} \dot{V}_{N_{2, \text { in }}}}{\dot{V}_{C_{4, \text { in }}}} \\
& S_{C_{x} H_{y}}=x \cdot \frac{\dot{n}_{C_{x} H_{y, \text { out }}}}{\dot{n}_{C H_{4, \text { in }}}-\dot{n}_{C H_{4, \text { out }}}}=x \cdot \frac{\frac{{ }_{C_{x} H_{y, \text { out }} / R F_{C} C_{y}}}{A_{N_{2, \text { out }} / R F_{N_{2}}}} \dot{V}_{N_{2, \text { in }}}}{\dot{V}_{C H_{4, \text { in }}}-\frac{{ }_{C_{x} H_{y, \text { out }} / R F_{C_{x} H_{y}}}}{A_{N_{2, \text { out }} / R F_{N_{2}}}} \dot{V}_{N_{2, \text { in }}}}
\end{aligned}
$$




\section{RESULTS AND DISCUSSION}

\subsection{Physical-chemical properties of the Mo/ZSM-5 catalysts}

The main features of the catalysts prepared by solvothermal synthesis under supercritical conditions (SC-STS) and impregnation (IMP) are discussed below. The presence of crystalline $\mathrm{MoO}_{2}$ phase after SC-STS-E and prior to calcination was confirmed by XRD (Figure S1). Comparing SEM-EDX results on the effective metal loading among the samples (Table 1), it seems that the addition of diluted ethanol in the solvent phase helped to incorporate Mo species to the zeolite support in SC-STS-E. The metal loss by SC-STS in the absence of reducing agent is, however, comparable to that obtained by impregnation. As a result of the different effective Mo loading, SCSTS-E has the lowest specific surface in comparison to SC-STS, IMP and the pristine ZSM-5. The low pore volume of IMP, however, suggests that the distribution of Mo is somehow producing a more relevant pore blockage that for SC-STS and SC-STS-E catalysts (Figure $1 \mathrm{~d}$ and Table 1 ).

The evaluation of the total acidity of the Mo/ZSM- 5 samples by $\mathrm{NH}_{3}$-TPD revealed that the initial bimodal (weak and strong) acidity distribution of the fresh zeolite was tuned by the effect of Mo incorporation (see Table 1 and Supporting Information, Figure S2). In the IMP synthesis the strong acid sites were reduced, whereas in the case of the supercritical conditions the strongest acid sites disappeared completely. Taking into account the similar metal loading employed in both SC-STS and IMP cases, the absence of strong acidity in the SC-STS samples suggests a better dispersion of Mo at the zeolite pores. This was confirmed by both CO-FTIR (Figure S3) [31] and XPS analyses. Table 1 shows the atomic distribution at the catalyst surface, i.e. Mo/(Si+Al) ratio, quantified from XPS measurements. It is observed that the Mo content at the surface decreases 
in the order IMP > SC-STS > SC-STS-E. Consequently, it can be assumed that Mo bulk dispersion qualitatively increases the other way around, i.e. SC-STS-E > SC-STS > IMP. As a result of the different metal-support interaction provided by the different synthesis methods, the surface Si/Al ratio differs among the fresh catalytic samples. The lower Si/Al value calculated for the IMP sample may indicate higher dealumination and/or greater presence of aluminium molybdate species at the external catalyst surface, as it will be discussed later.

Table 1. Summary of physical-chemical properties of the different Mo-ZSM5 catalysts

\begin{tabular}{|c|c|c|c|c|c|c|c|c|c|}
\hline Sample & $\begin{array}{c}\% w t . \mathrm{Mo}^{\mathrm{a}} \\
(\%)\end{array}$ & $\begin{array}{c}\mathrm{S}_{\mathrm{g}}{ }^{\mathrm{b}} \\
\left(\mathrm{m}^{2} / \mathrm{g}\right) \\
\end{array}$ & $\begin{array}{c}V_{p}^{b} \\
\left(\mathrm{~cm}^{3} / g\right)\end{array}$ & $\begin{array}{c}\text { Total } \\
\text { acidity }^{\mathrm{c}}\end{array}$ & $\begin{array}{l}\text { Weak } \\
\text { acidity }^{c}\end{array}$ & $\begin{array}{l}\text { Medium } \\
\text { acidity }^{c}\end{array}$ & $\begin{array}{l}\text { Strong } \\
\text { acidity }^{c}\end{array}$ & $\begin{array}{c}\mathrm{Mo} /(\mathrm{Al}+\mathrm{Si})^{\mathrm{d}} \\
(-)\end{array}$ & $\begin{array}{c}\mathrm{Si} / \mathrm{Al}^{\mathrm{d}} \\
(-)\end{array}$ \\
\hline H-ZSM-5 & - & $284 \pm 4$ & 0.125 & 1.22 & $31 \%$ & $26 \%$ & $43 \%$ & - & - \\
\hline SC-STS & $4.2 \pm 0.2$ & $271 \pm 6$ & 0.128 & 0.65 & $38 \%$ & $62 \%$ & $0 \%$ & 0.11 & 8.7 \\
\hline SC-STS-E & $4.7 \pm 0.1$ & $253 \pm 5$ & 0.120 & 0.59 & $39 \%$ & $61 \%$ & $0 \%$ & 0.10 & 9.6 \\
\hline IMP & $4.3 \pm 0.5$ & $271 \pm 6$ & 0.117 & 0.99 & $21 \%$ & $45 \%$ & $34 \%$ & 0.15 & 7.0 \\
\hline \multicolumn{10}{|c|}{${ }^{a}$ Weight percentage obtained by EDX analysis } \\
\hline \multicolumn{10}{|c|}{${ }^{\mathrm{b}}$ Textural properties determined by $\mathrm{N}_{2}$-adsorption: specific surface area $\left(\mathrm{S}_{\mathrm{g}}\right)$ and total pore volume $\left(\mathrm{V}_{\mathrm{p}}\right)$} \\
\hline \multicolumn{10}{|c|}{${ }^{\mathrm{c}}$ Acidity retrieved from $\mathrm{NH}_{3}-\mathrm{TPD}$} \\
\hline
\end{tabular}

Figure 2 shows the XPS spectra concerning the surface oxidation state of Mo in the fresh (Figure $2 \mathrm{a}$ and $2 \mathrm{~b}$ ) and spent (Figure $2 \mathrm{c}$ and $2 \mathrm{~d}$ ) samples, as well as the distribution of the carbon binding nature in the coked samples after reaction (Figure 2e and 2f). For the sake of comparison, the two samples with the most similar final Mo content, i.e. SC-STS and IMP, were selected. Mo $3 d_{5 / 2}$ photoemission spectra of fresh calcined samples (Figures $2 a$ and $2 b$ ) revealed that Mo was fully oxidized and $(94 \%)$ of Mo (VI) for SC-STS and IMP, respectively. The predominant Mo (VI) state in the fresh samples was also confirmed by Raman measurements (Figure S4). The oxidation state 
$\mathrm{Mo}(\mathrm{VI})$ is normally related to $\mathrm{MoO}_{3}$ dispersed on the zeolite surface whereas Mo (V) has been associated with $\mathrm{Mo}^{5+}$ species present in bulk $\mathrm{MoO}_{3}[32]$. This would confirm the presence of comparatively bigger Mo aggregates at the outer surface of the IMP sample.

During MDA in the presence of methane as reducing agent, a number of Mo species coexist in the SC-STS sample, presenting different oxidation states: IV, V, VI and $\delta$. This latter oxidation state is attributed to the molybdenum carbide species, $\mathrm{Mo}_{2} \mathrm{C}$, which is often claimed to be the active species for this reaction, $[9,22,33]$. The signal of the Mo $3 d_{5 / 2}$ photoemission spectra, of the coked IMP sample (Figure $4 \mathrm{c}$ ), could not be detected. The absence of Mo signal can be attributed to the thickness of the outer coke deposits after 15 hours on stream. It is probably exceeding the penetration depth threshold of the technique $(<10 \mathrm{~nm})$. The different C1s photoemission spectra (Figure 2e and $2 \mathrm{f}$ ) after $15 \mathrm{~h}$ MDA also corroborated that the catalyst coking is more representative in the case of the samples prepared by impregnation.

The $\mathrm{C}-\mathrm{C}$ bond represents hard coke from polyaromatic or pre-graphitic species formed at strong acid sites whereas the $\mathrm{C}-\mathrm{O}-\mathrm{C}$ and $\mathrm{O}-\mathrm{C}=\mathrm{O}$ bonds are more related to the graphitic coke formed at the oxycarbide active sites $\left(\mathrm{MoO}_{x} \mathrm{C}_{y}\right)[33,34]$. These results suggest that the higher Mo dispersion in the case of the SC-STS sample seems to lead to a partial inhibition of the hard coke formation, maybe contributing to a different catalyst deactivation mechanism.

TEM analysis supported the previous findings on the effect of the different synthesis methods on the initial Mo dispersion and catalyst coking of the evaluated samples. TEM analysis also revealed that the dispersion of Mo species was somehow better for the samples synthesized by the SC-STS-E method. Figure 3a shows a TEM image of the 
IMP sample. The presence of nanoclusters (darker contrast) with a fairly homogeneous distribution located at the outer zeolite surface is clearly observed. Similar bright-field TEM images were acquired for SC-STS and SC-STS-E, although the micrographs did not provide clear evidence of any Mo species. This motivated the use of HAADF-STEM. The dark-field analysis revealed the presence of very well dispersed dots with brighter contrast corresponding to Mo species within the zeolite channels. Taking into account the diameter of zeolite micropores $(0.53 \mathrm{~nm})$, the bright inner dots observed in Figure 3b (SC-STS-E sample) could consist of clusters of very few atoms of Mo species or even single Mo atoms exchanged at the zeolite framework. Figures $3 \mathrm{c}$ and $3 \mathrm{~d}$ provide a qualitative description of Mo distribution in the fresh IMP and SC-STS-E samples as well as its probable effect on the coking mechanism during the MDA process. 

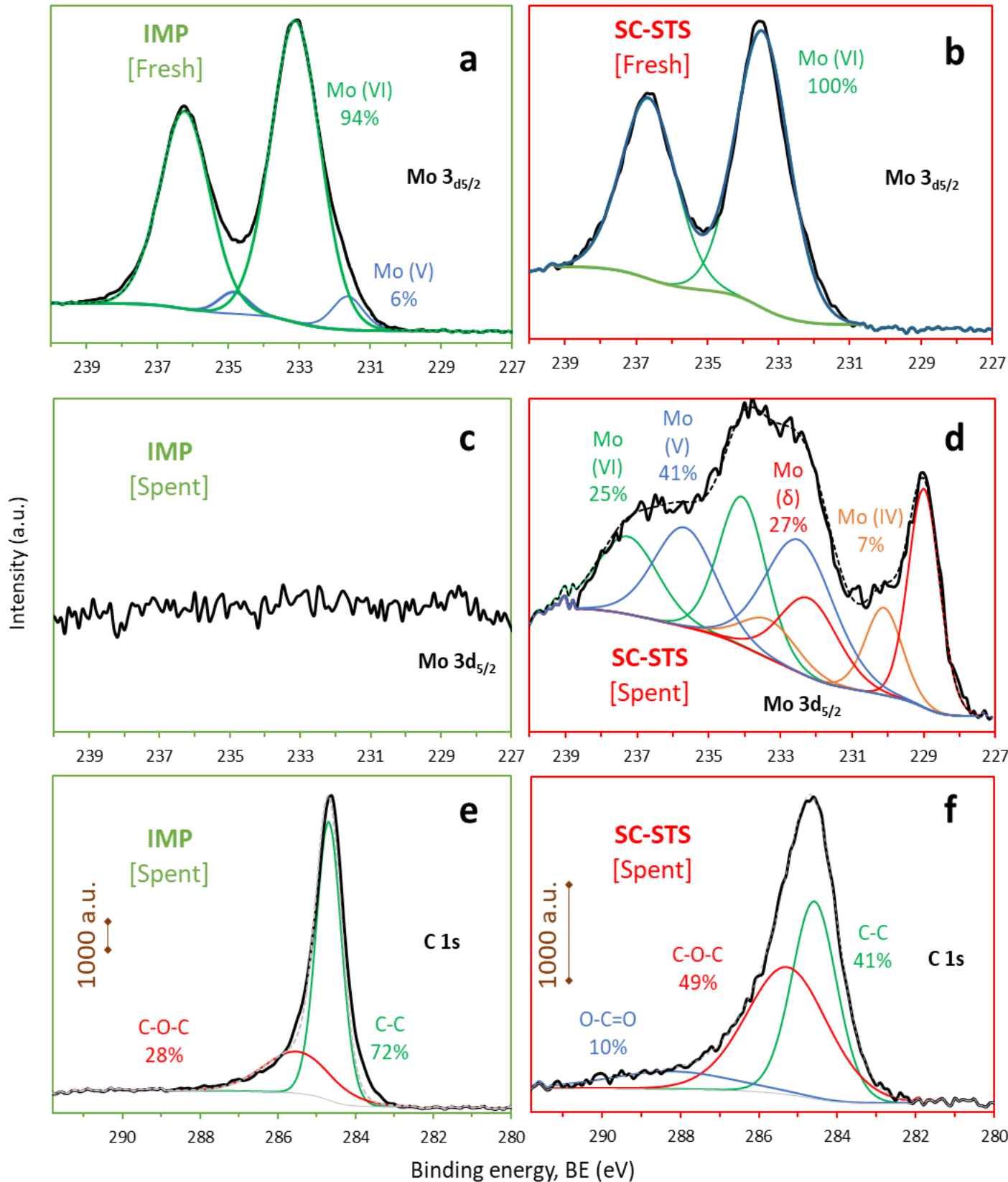

Figure 2. X-ray Mo3d $d_{5 / 2}$ photoemission spectra of fresh Mo/ZSM-5 catalysts prepared by (a) IMP and (b) SC-STS. Mo3d $d_{5 / 2}$ photoemission spectra of spent (c) IMP and (d) SC-STS samples after $15 \mathrm{~h}$ on stream. C1s photoemission spectra of spent (e) IMP and (f) SC-STS samples after $15 \mathrm{~h}$ on stream

The comparison between both coked samples after 15 hours on stream under MDA conditions clearly revealed the different nature of their most representative carbon deposits differs between them. The catalyst prepared by SC-STS-E shows the presence 
of Mo-associated carbon in the form of well dispersed carbide clusters $\left(\mathrm{MoC}_{\mathrm{x}}\right)$ at the zeolite surface (Figure $3 \mathrm{f}$ ). These clusters appear to be surrounded by a very thin layer of soft coke as it is revealed by the STEM-EDX spectra (Figure 3f, spectrum 5).
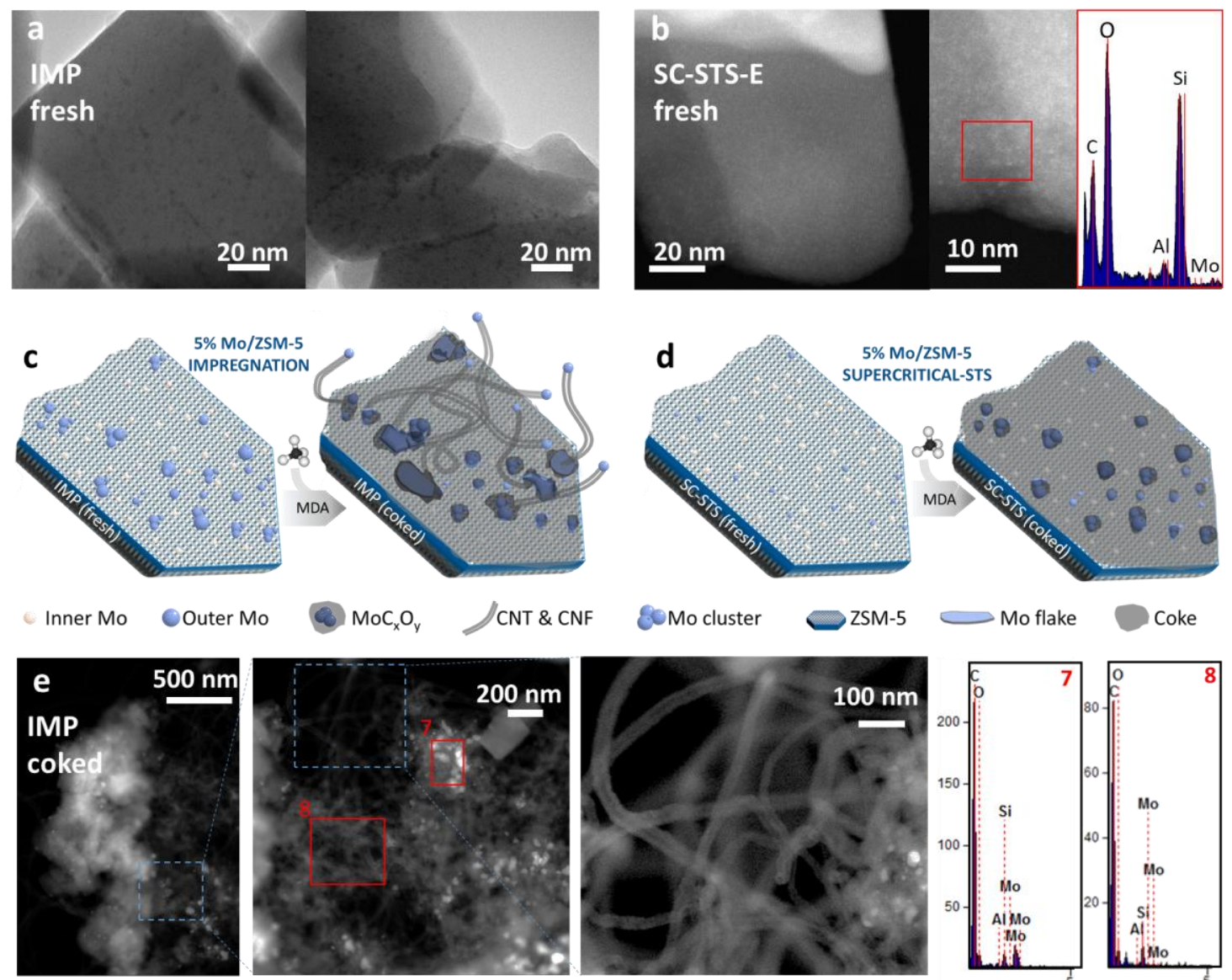

(8) $\mathrm{MoC}_{\mathrm{x}} \mathrm{O}_{\mathrm{y}} \mathrm{CNT} \& \mathrm{CNF}$

So cluster

$\Longrightarrow$ ZSM-5
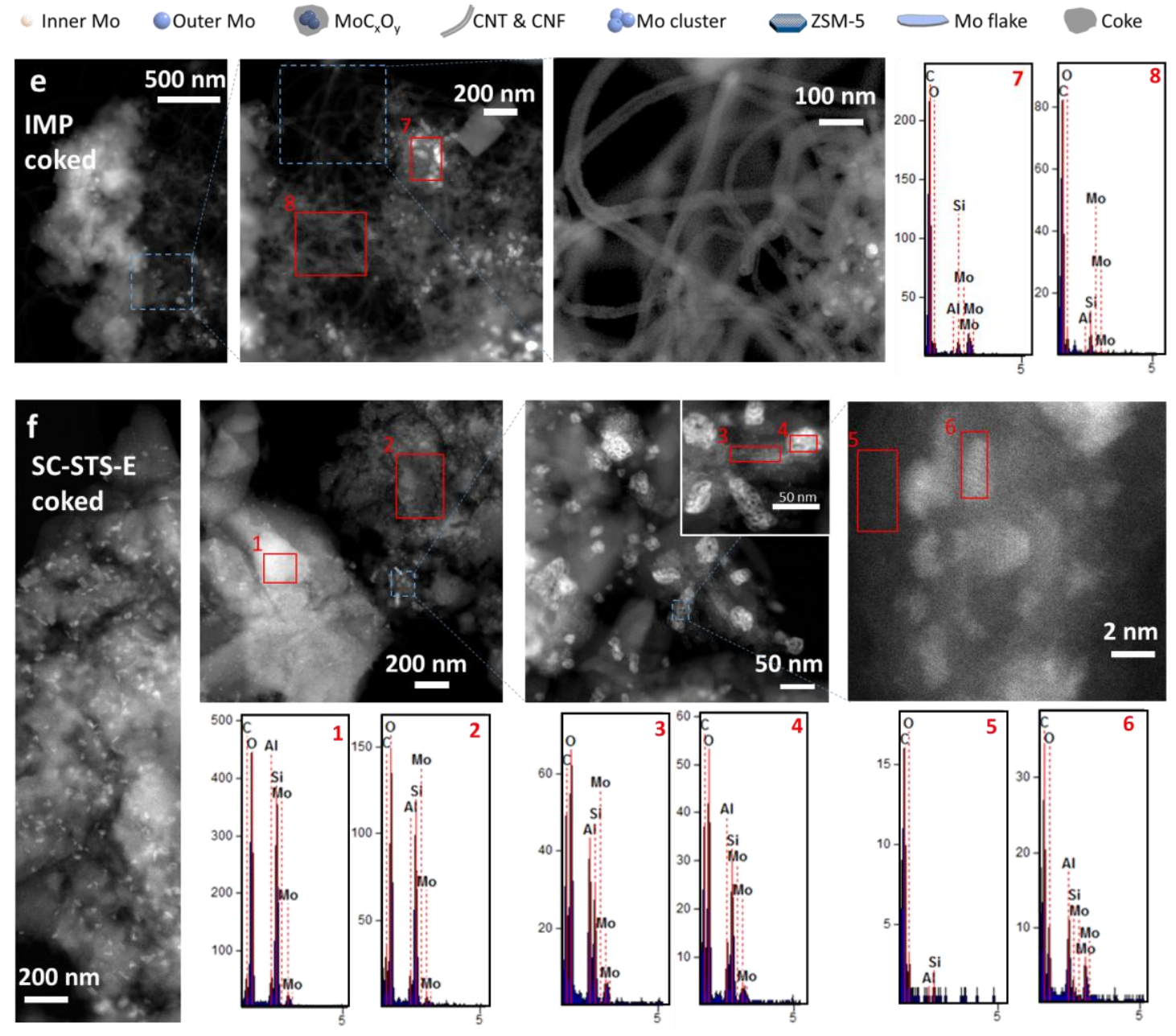
Figure 3. (a) TEM-EDX micrographs of fresh 5\%Mo/ZSM-5 prepared by incipient wetness impregnation (IMP), showing Mo clusters at the external surface. (b) HAADF-STEM of fresh 5\%Mo/ZSM-5 prepared by supercritical solvothermal synthesis with ethanol (SC-STS-E) showing fine Mo dispersion. (c) - (d) Conceptual drawing of Mo distribution along the zeolite support for fresh and spent 5\%Mo/ZSM-5 by IMP and SC-STS-E, respectively. The poorer Mo dispersion of IMP results in Mo clustering at the fresh zeolite surface and more intense coking during MDA. (e) - (f) HAADF-STEM images of spent IMP and SCSTS-E catalysts, respectively, after 15 hours MDA and EDX spectra of selected areas, illustrating the different coking behaviour of the samples as a result of the initial Mo dispersion

In contrast, the predominant carbon species in the coked IMP sample are carbon nanotubes and nanofibers, CNT/CNF, located out of the zeolite surface (Figure 3e).

The different nature of coke deposits was corroborated by Raman spectroscopy. Figure 4a shows the Raman spectra and a 5-peak-based deconvolution of the intense signals associated with deposited carbon species for the spent IMP and SC-STS-E samples. Typically, the Raman shift around $1200 \mathrm{~cm}^{-1}$ is assigned to aliphatic $\mathrm{C}-\mathrm{H}$ bounds, the D band around $1350 \mathrm{~cm}^{-1}$ relates to the aromatic structures poorly structured or disordered, the so-called $D_{3}$ band $\left(1430 \mathrm{~cm}^{-1}\right)$ is assigned to structural defects of aromatic domains with poor organization, the $\mathrm{G}$ band (around $1590 \mathrm{~cm}^{-1}$ ) relates to more structured graphitized structures whereas $D_{2}$ represents the $D$ echo band [35]. On this regard, it is observed that the ratio between $G$ and $D$ band intensities is greater in the case of the spent IMP after a similar time on stream, specifically: $\left(\mathrm{I}_{\mathrm{D}} / \mathrm{I}_{\mathrm{G}}\right)_{\mathrm{IMP}}=0.82$ and $\left(I_{D} / I_{G}\right)_{S C-S T S-E}=1.11$.

Probably, the growth of structured CNT is caused by the presence of large Mo nanoparticles (as a result of a poorer metal dispersion) acting as nucleation points. These large Mo nanoparticles detach from the zeolite surface as the CNT grow and 
become isolated and flushed away during an eventual regeneration step in the presence of an oxidizing agent. The reported irreversibility of the reactionregeneration cycles for highly-loaded Mo/ZSM-5 catalysts ( $\geq 5 \%$ wt. Mo) $[2,36]$, i.e. activity loss between consecutive MDA cycles, could be thus partially explained by the metal loss during the combustion of the CNT/CNF. Other reported factors are the formation of aluminium molybdate phase, framework dealumination and degradation of the zeolite crystallinity $[2,36]$.

These three later factors were further evaluated by ${ }^{27} \mathrm{Al}$ MAS NMR characterization. Figure $4 \mathrm{~b}$ shows the ${ }^{27} \mathrm{Al}$ MAS NMR spectra of the fresh IMP, SC-STS and SC-STS-E catalysts. The chemical shifts at 50 and $55 \mathrm{ppm}$ belong to framework tetrahedral aluminium whereas the band at $0 \mathrm{ppm}$ indicates the presence of extra-framework octahedral aluminium. The shifts at +14 and -14 are attributed to the hydrated and (resonant) non-hydrated forms of the aluminium molybdate phase, i.e. $\left[\mathrm{Al}(\mathrm{OH})_{n}\left(\mathrm{H}_{2} \mathrm{O}\right)_{6-}\right.$ $n]_{n}\left(\mathrm{MoO}_{4}\right)(\mathrm{n}=1$ or 2$)$ and $\mathrm{Al}_{2}\left(\mathrm{MoO}_{4}\right)_{3}$, respectively [37]. The last species appear as a result of a strong interaction between the molybdenum and the zeolite aluminium species. The coexistence of hydrated and non-hydrated $\mathrm{Al}_{2}\left(\mathrm{MoO}_{4}\right)_{3}$ crystallites would suggest that this species is present both well dispersed in the catalyst bulk and at the surface, whereas a single band at +14 would indicate the presence of external $\mathrm{Al}_{2}\left(\mathrm{MoO}_{4}\right)_{3}$ only [37].

Figure $4 \mathrm{~b}$ reveals that Mo interaction with framework $\mathrm{Al}$ is significantly more intense for the samples prepared by solvothermal synthesis. In particular, the smooth dealumination in IMP leads to the formation of external $\mathrm{Al}_{2}\left(\mathrm{MoO}_{4}\right)_{3}$ crystalline species 
(band at $+14 \mathrm{ppm}$ ) whereas the dealumination of SC-STS-E support leads to the formation of internal aluminium molybdate structures.

On the one hand, the low interaction of Mo with the aluminium of the zeolite in IMP may indicate that most Mo species would remain as external $\mathrm{MoO}_{3}$ aggregates at the catalyst surface. $\mathrm{NH}_{3}$-TPD (Figure S2), FTIR spectroscopy with CO adsorption (Figure S3) and TEM-STEM (Figure 3) results point to the same conclusion.

On the other hand, it has been reported that the external aluminium molybdate may be detrimental for the catalytic performance. However, its presence within the bulk structure apparently does not affect the performance negatively [37].

Comparing the NMR spectra of fresh and regenerated samples (Figure S5), it is clear that the oxidative regeneration of coked samples promotes both dealumination and formation of external $\mathrm{Al}_{2}\left(\mathrm{MoO}_{4}\right)_{3}$. Although this effect is very noticeable even for the SC-STS-E sample, XRD results indicate that the crystalline structure of the bulk catalyst remains unaltered after one reaction-regeneration cycle (Figure 4c). 

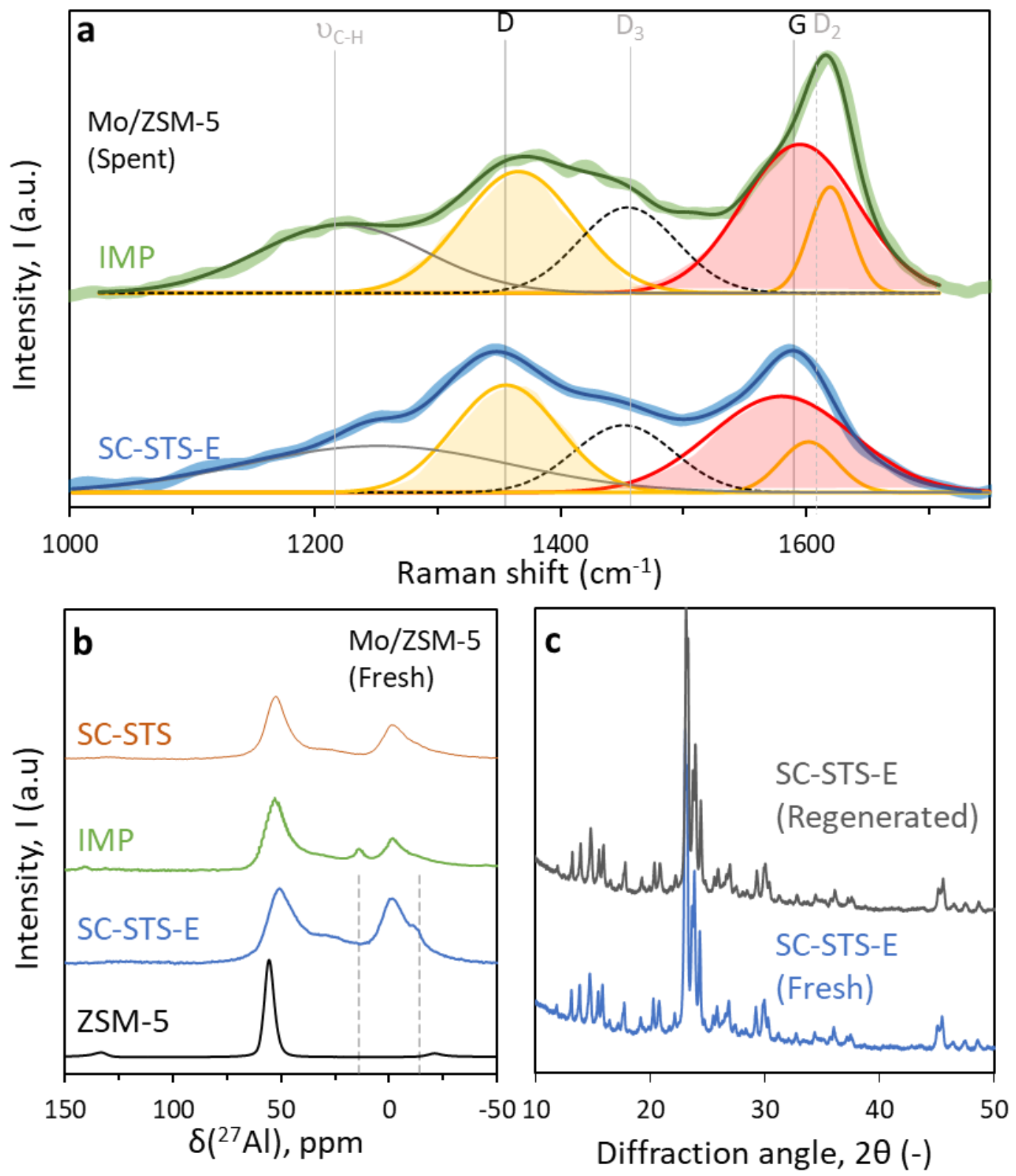

Figure 4. a) Deconvoluted Raman spectra of spent samples prepared by impregnation (IMP) and supercritical solvothermal synthesis with ethanol addition (SC-STS-E) after 15 h MDA; b) ${ }^{27}$ Al MAS NMR spectra of fresh IMP, SC-STS and SC-STS-E samples; c) XRD diffractogram of fresh and regenerated SCSTS-E sample after $15 \mathrm{~h}$ MDA 


\subsection{Catalyst performance evaluation}

The catalytic performance of the synthesized samples for methane dehydroaromatization was evaluated under the experimental conditions described in subsection 2.3. Figure 5a shows the transient methane conversion and overall hydrocarbon yield of the 5 wt.\% Mo/ZSM- 5 catalysts prepared by SC-STS, SC-STS-E and IMP whereas Figure 5b represents the yield to the major product of interest, i.e. benzene, for the above mentioned catalysts. Figure 5a reveals that the SC-STS sample outperforms the IMP by almost $20 \%$ higher conversion and $17 \%$ hydrocarbon productivity after 15 hours on stream. Moreover, the supercritical solvothermal synthesis promoted by the use of ethanol as reducing agent in the solvent phase (SCSTS-E) led to an unprecedented catalytic performance ascribed to an enhanced atomically dispersed Mo distribution along the zeolite channels. For instance, the sample SC-STS-E outperforms the conventional IMP catalyst by $45 \%$ and $36 \%$ in terms of methane conversion and products yield after 15 hours on stream. The different performance of SC-STS and SC-STS-E in terms of methane conversion can be ascribed to the different Mo content and distribution along the samples (Table 1). The outstanding hydrocarbon yield stability of SC-STS-E suggests that the intrinsic catalyst deactivation, i.e. methane conversion decay, only seems to impact the production rate of coke and $\mathrm{C}_{10+}$ species for this sample. The reaction progress appears to enhance the process selectivity towards $C_{2}-C_{10}$ species. This finding can be tentatively attributed to more effective Mo-Al interactions as a result of: (i) a comparatively finer metal dispersion; (ii) lower catalyst acidity and (iii) minimized accumulation of Mo as aggregated surface deposits. The catalyst deactivation rate of each sample was quantified in the period $5-10 \mathrm{~h}$ on stream (Figure S6), being the conversion decay 
$\left(\mathrm{dX}_{\mathrm{CH}_{4}} / \mathrm{dt}\right):-0.35,-0.31$ and $-0.24(\% / \mathrm{h})$ for IMP, SC-STS and SC-STS-E, respectively. This result is in agreement with the above-discussed characterization results, illustrating that the synthesis method and Mo dispersion play a key role in the MDA performance of these Mo/ZSM-5 based catalysts. The smooth decay of benzene yield against time for every sample shown in Figure $5 b$ is normally attributed to the loss of shapeselectivity within the zeolite pores during the progressive blocking caused by coke. Consequently, the reaction progress leads to a reduction of the contact time and, thus, to an increase of the production of $C_{2}$ species.
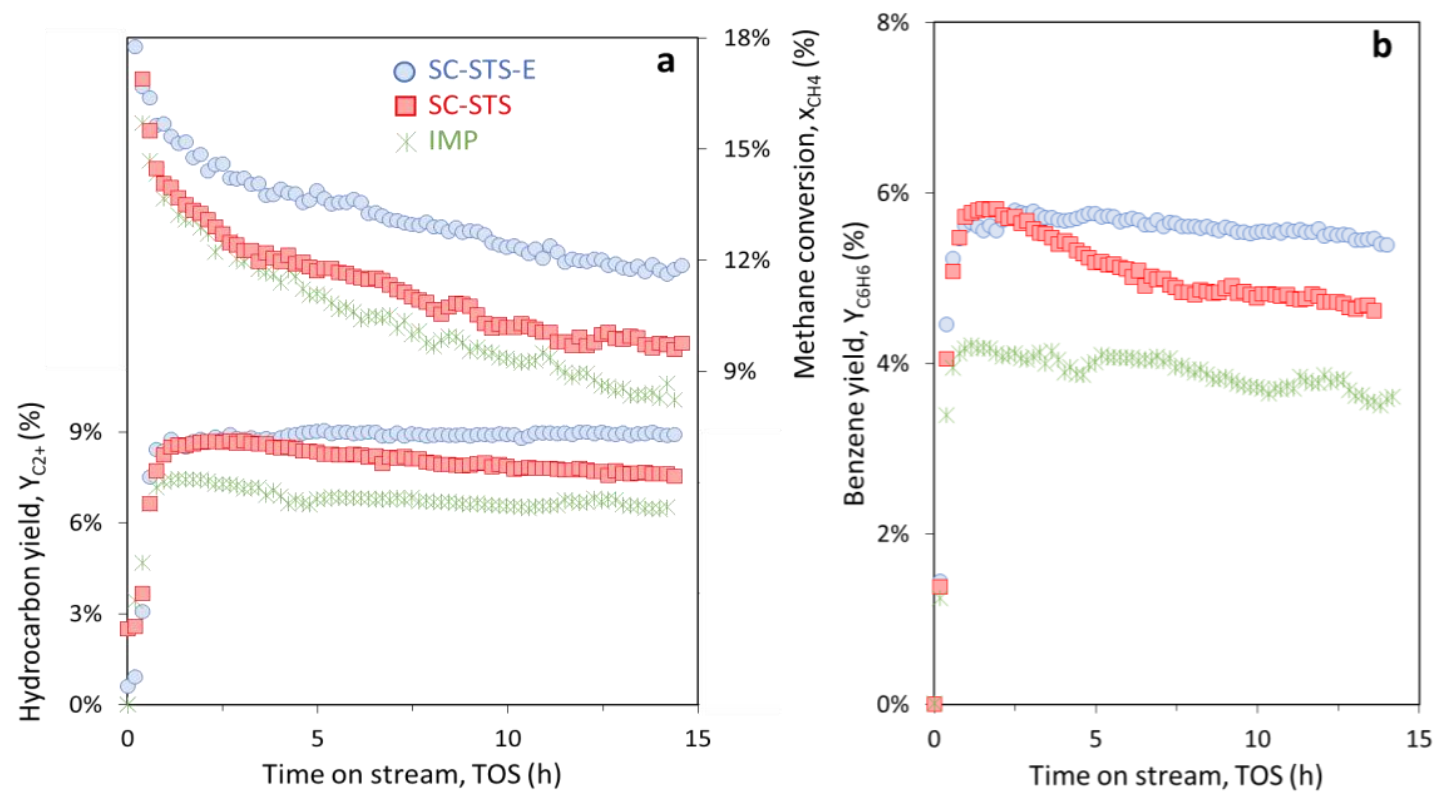

Figure 5. Experimental methane conversion, overall hydrocarbon yield (a) and benzene yield (b) for different 'SC-STS' and 'IMP' 5\%Mo/ZSM-5 samples. Operational conditions: $700^{\circ} \mathrm{C}, 1500 \mathrm{~mL} / \mathrm{g}_{\text {cat }} \mathrm{h}, 0.5 \mathrm{~g}_{\text {cat }}$

The transient products distribution of SC-STS-E is depicted in Figure 6a. Apart from unreacted methane, ethylene, benzene, naphthalene and hydrogen, small amounts of ethane and toluene as well as traces of propylene, xylene and $\mathrm{C}_{10+}$ polyaromatics were detected at the outlet gas of the MDA process. Additionally, CO was detected during 
the induction period as a result of the reduction of molybdenum oxide species into oxycarbides and $\mathrm{Mo}_{2} \mathrm{C}$ in the presence of methane.

The total amount of coke deposits accumulated on IMP and SC-STS-E samples after 15 hours on stream was $51.2 \mathrm{mg} / \mathrm{g}_{\text {cat }}$ and $46.0 \mathrm{mg} / \mathrm{g}_{\text {cat, }}$, respectively. This illustrates that the proposed supercritical synthesis method can reduce coke production by $10 \%$ even obtaining higher methane conversion. Normalizing coke production with respect to the total converted methane at the selected sampling time, IMP and SC-STS-E samples produced 1.22 and $0.99 \mathrm{~g} /\left(\mathrm{g}_{\text {cat }} \cdot \mathrm{mol}_{\mathrm{CH} 4 \text { _conv }}\right)$, respectively. These numbers indicate a noticeable $18 \%$ reduction of MDA selectivity towards coke species in the case of the sample synthesized by SC-STS-E. In both cases, the total coke accumulation was quantified monitoring the $\mathrm{CO}_{\mathrm{x}}$ signal during coke combustion in the presence of diluted oxygen $\left(\mathrm{N}_{2}: \mathrm{O}_{2}=19: 1,2400 \mathrm{~mL} / \mathrm{g}_{\text {cat }} \mathrm{h}\right)$ at $580^{\circ} \mathrm{C}$. The thermogravimetic analysis of the SC-STS-E sample suggests that the vast majority of the coke species are burned out at this temperature (Figure S7).

According to recent reviews in literature $[7-11,20,38]$, it has been well established that the optimum Mo loading of MDA catalysts is in the range $3-6 \mathrm{wt} \%$ Mo. In this regard, Han et al. [2] investigated the effect of metal loading on the different coke type distribution after $10 \mathrm{~h}$ MDA on Mo/ZSM-5 prepared by impregnation and found that the ratio between low-temperature (soft, $\mathrm{C}_{\mathrm{S}}$ ) and high-temperature (hard, $\mathrm{C}_{\mathrm{H}}$ ) coke (i.e. Mo-associated and polyaromatics coke, respectively) remained nearly constant at wt. Mo loadings in the range $3 \%-5 \%\left(C_{S} / C_{H}=0.75\right)$ whereas it increased up to 1.22 for a sample containing $7 \%$ Mo. It confirmed that the presence of Mo 
aggregates at the surface promotes the selective generation of hard coke, thus, leading to a lower active sites accessibility and faster deactivation.
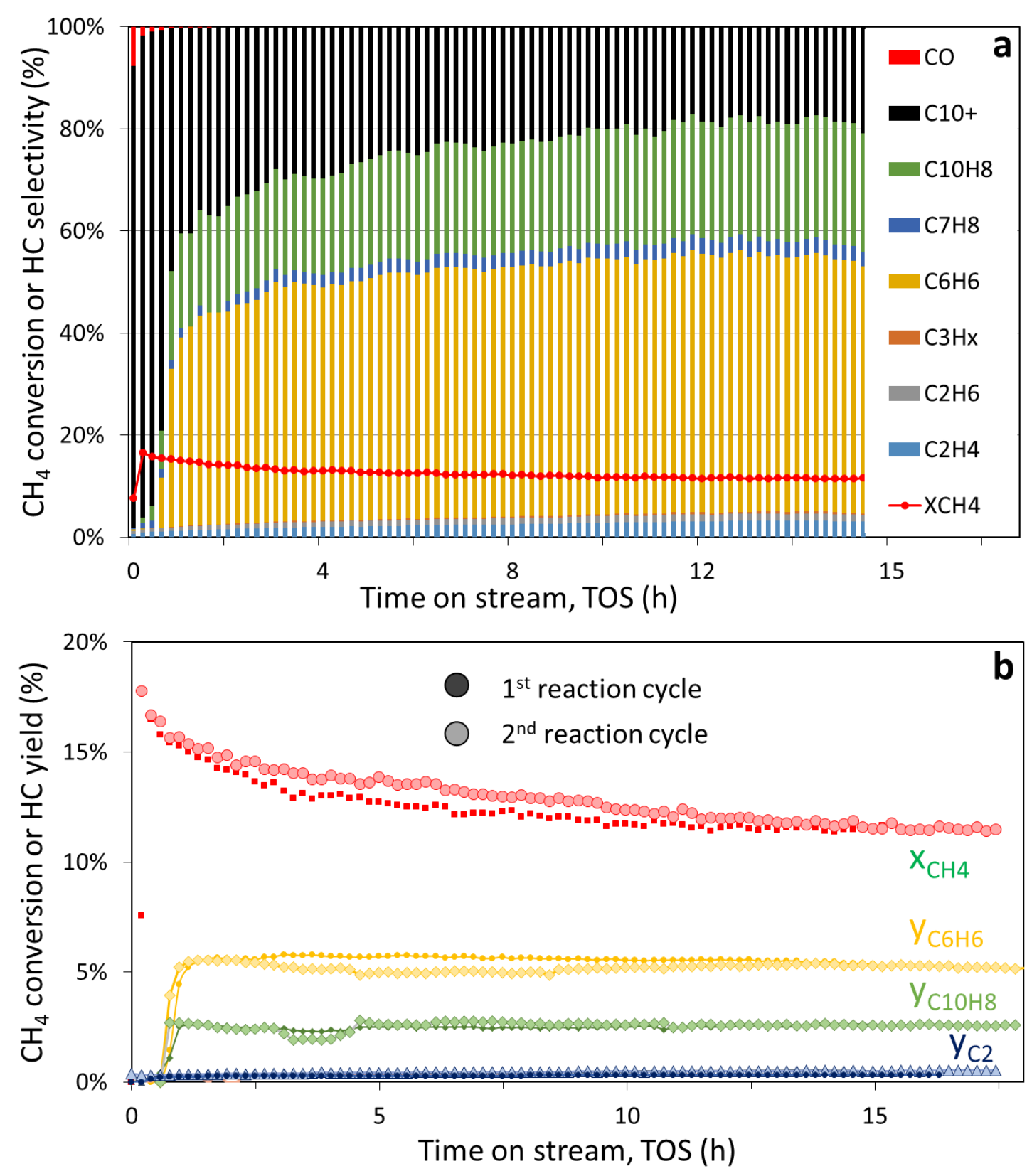

Figure 6. a) Experimental methane conversion and hydrocarbon selectivities for the catalytic sample SC-

STS-E; b) effect of reaction-regeneration cycle on the catalytic performance of SC-STS-E. Reaction conditions: $700^{\circ} \mathrm{C}, 1500 \mathrm{~mL} / \mathrm{g}_{\text {cat }} \mathrm{h}, 0.5 \mathrm{~g}_{\text {cat }}$ 
In a recent fundamental study, Kosinov et al. [39] suggest that the Mo centres confined inside the pores seem to be the catalytic active site initiators. In contrast, larger species at the external surface, that often dominate spectroscopy characterization, are found to be catalytically irrelevant. In addition, these somehow undesired external Mo clusters can potentially undergo sintering during regeneration steps, thus, leading to activity and selectivity decay along consecutive reaction-regeneration cycles [36]. In order to check the regeneration capacity of the highly-dispersed $5 \% \mathrm{Mo} / \mathrm{ZSM}-5$ samples prepared by SC-STS-E, we performed two consecutive 18h MDA reaction cycles including an intermediate regeneration step with diluted oxygen at the following operational conditions: $5 \% \mathrm{O}_{2} / \mathrm{N}_{2}, 580^{\circ} \mathrm{C}$ and $2400 \mathrm{~mL} / \mathrm{g}_{\text {cat }} \mathrm{h}$. Additionally, in order to evaluate potential structural changes, the X-ray diffraction patterns of both fresh and regenerated SC-STS-E samples (after two MDA reaction cycles) were measured and compared.

Figure $6 \mathrm{~b}$ illustrates that there is not any evidence of crystallinity loss and/or formation of defects or new crystalline phases as a result of catalyst coking and regeneration. Figure $6 \mathrm{~b}$ suggests that the catalytic performance of the SC-STS-E sample remained unaltered after one reaction-regeneration cycle, as Kosinov et al. [36] previously found working at similar regeneration conditions for atomically-dispersed low-loaded 1\%Mo/ZSM-5 samples. In this case, XRD results shown in Figure 4c already confirmed the stability and crystallinity of the bulk catalyst during the coking and regeneration processes. Still, some Al coordination changes were detected by ${ }^{27} \mathrm{Al}$ MAS NMR between the fresh and regenerated SC-STS-E sample. 
The results presented in this paper confirm that the SC-STS-E method represents a highly efficient and scalable (continuous) process to synthesize highly dispersed Mo/ZSM- 5 with up to 5 wt. \% metal loading. The negligible presence of superficial Mo clusters confers the sample with the highest long term stability for MDA in terms of methane conversion and $\mathrm{C}_{2+}$ yield among the experimental results reported in literature using similar parent zeolites, metal loadings and spatial velocities as the ones described in the present work $[2,32,40-46]$. The experimental results reported in this work were compared with existing MDA literature data related to transient methane conversion and aromatics yield on fixed beds of 5-6 wt.\% Mo/ZSM-5 (or MCM-22) working at $700^{\circ} \mathrm{C}$, atmospheric pressure and $1500 \mathrm{~mL} / \mathrm{g}_{\text {cat }} \mathrm{h}$ for, at least, 8 hours on stream. Cyclic reaction-regeneration operation results were also discarded from this comparison. The publications subjected to the MDA performance comparison have been summarized in Table 2 and plotted in Figure 7. We can conclude that the experimental conditions addressed by Liu et al. [41] led to the best long term methane conversion amongst all results reported in literature. As the authors claim, they were able to promote the catalytic activity and lifetime by preparing hierarchical ZSM- 5 by hydrothermal synthesis. The hierarchical porosity and suitable acidity were pointed as the most influencing factors contributing to their excellent catalytic performance. The long-term conversion presented by these authors is, in fact, the only one that outperforms the results disseminated in the present work, based on the supercritical solvothermal synthesis of $5 \% \mathrm{Mo} / \mathrm{ZSM}-5\left(\mathrm{SiO}_{2} / \mathrm{Al}_{2} \mathrm{O}_{3}=23\right)$.

Our methane conversion results resemble the values reported by Yin et al. (2014) [39], who employed 6\% Mo/MCM-22 using an in-house synthesized nano-sized MCM-22 (40 $\mathrm{nm}$ crystal size) followed by impregnation of Mo (see also Table 2). In terms of $\mathrm{C}_{2+}$ 
yield, none of the previous literature results can reach the excellent and nearly constant aromatics yield along 15 hours on stream reported in this work. Again, the catalysts and experimental conditions of Liu et al. (2018) [41], Yin et al. (2014) [46] and Song et al. (2007) [32] modified the ZSM-5 support by hydrothermal post-synthesis in $\mathrm{Al}\left(\mathrm{NO}_{3}\right)_{3}$ aqueous solution to create a uniform micropore network with suitable acidic strength.-These modifications yielded the highest aromatics productivity reported up to date. Considering that the values reported in the literature correspond to different operational conditions (i.e. methane dilution, partial pressure, space velocity, ...) we compared also the best reported results in terms of productivity, last column of Table 2. Our reported values are in the same order of aromatics productivity with lower catalyst deactivation rate.

In addition to the MDA results collected in Table 2 for comparison of analogous reaction systems to ours, a series of recent MDA research works have dealt with the use of additional co-catalyst features and/or strategies to extend the catalyst lifetime and enhance its stability and coke resistance. Table 3 summarizes the catalytic performance (i.e. methane conversion and aromatics yield, if available) of these reaction systems after 5 hours on stream. This TOS was selected for the sake of comparison with the results presented in Table 2. 

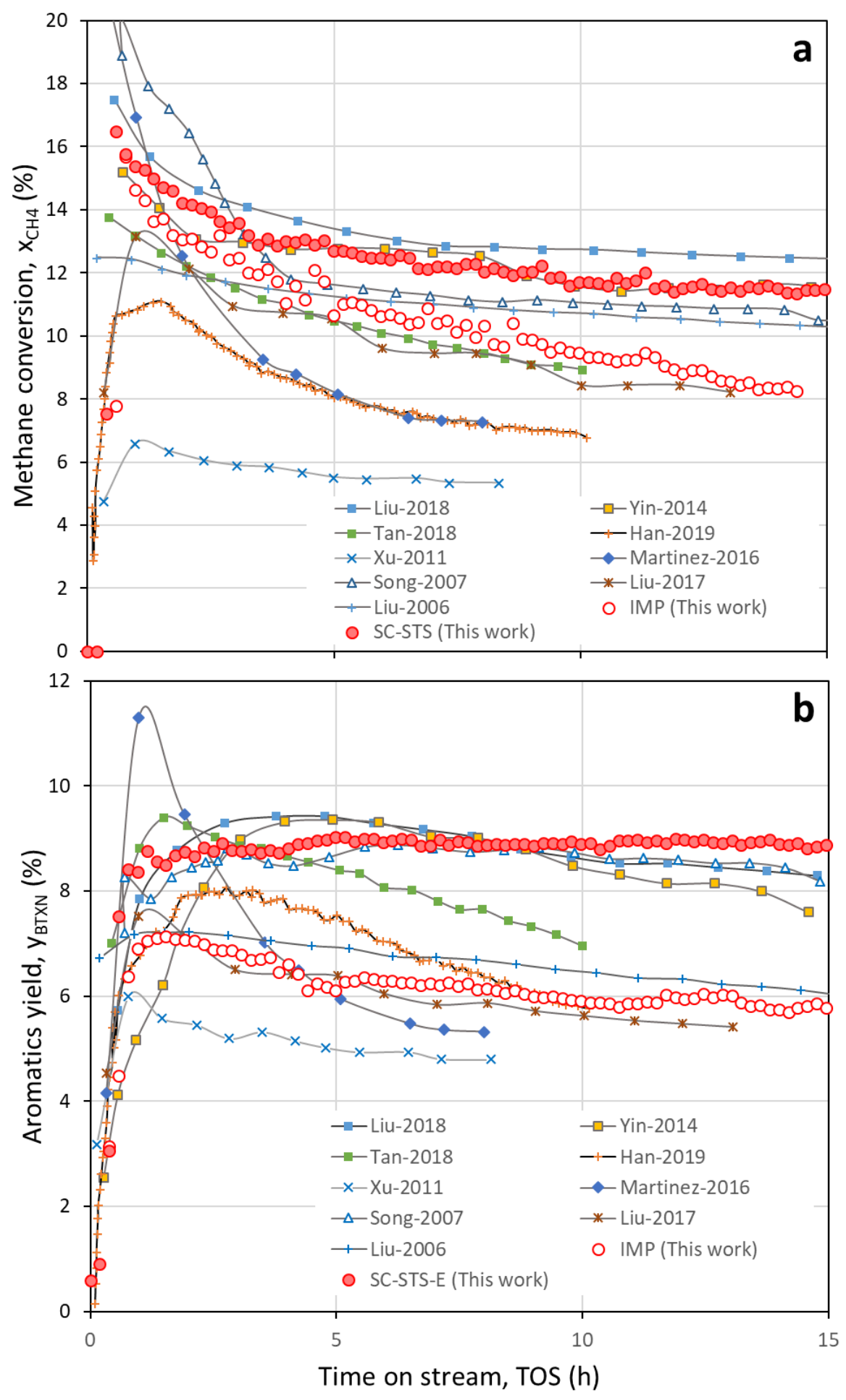

Figure 7. Comparison among the best long-term MDA results ( $>8 \mathrm{~h}$ ) on Mo/ZSM-5 catalysts at $700^{\circ} \mathrm{C}$ and $1500 \mathrm{~mL} / \mathrm{g}_{\text {cat }} \mathrm{h}$. The listed authors correspond to references: [2, 32, 40-46] 
Table 2. Literature review of long-term MDA performance (> 8h) on fixed beds of 6 wt.\% Mo/ZSM-5 based powder catalysts $\left(d_{p}=250-425 \mu \mathrm{m}\right)$ working at $700^{\circ} \mathrm{C}, 1500 \mathrm{~mL} / \mathrm{g}_{\text {cat }} \mathrm{h}$ and atmospheric pressure

\begin{tabular}{|c|c|c|c|c|c|c|c|}
\hline Reference & $\mathrm{Si} / \mathrm{Al}$ & $\mathrm{CH}_{4}: \mathrm{N}_{2}$ & $\mathrm{x}_{\mathrm{CH} 4}(5 \mathrm{~h})$ & $\mathrm{X}_{\mathrm{CH} 4}(15 \mathrm{~h})$ & $Y_{C 6+}(5 h)$ & $\mathrm{Y}_{\mathrm{C6+}}(15 \mathrm{~h})$ & $\mathrm{C}_{6+}(15 \mathrm{~h})\left(\mu \mathrm{mol} \mathrm{C}_{6+} / \mathrm{g}_{\mathrm{cat}} \mathrm{h}\right)$ \\
\hline Liu-2018 [41] & 30 & $90: 10$ & $13.3 \%$ & $12.4 \%$ & $9.4 \%$ & $8.3 \%$ & 834 \\
\hline Tan-2018 [42] & 25 & $90: 10$ & $10.5 \%$ & - & $8.4 \%$ & - & - \\
\hline Xu-2011 [43] & 20 & 92.5:7.5 & $5.5 \%$ & - & $5.0 \%$ & - & - \\
\hline Song-2007 [32] & 25 & $89.5: 10.5$ & $11.7 \%$ & $10.5 \%$ & $8.7 \%$ & $8.2 \%$ & 819 \\
\hline Liu-2006 [44] & 50 & $90: 10$ & $11.2 \%$ & $10.3 \%$ & $6.9 \%$ & $6.0 \%$ & 603 \\
\hline Liu-2017 [40] & 50 & $92.5: 7.5$ & $10.6 \%$ & - & $6.4 \%$ & - & - \\
\hline Martinez-2016 [45] & 16.5 & $90: 10$ & $8.2 \%$ & - & $6.0 \%$ & - & - \\
\hline Han-2019 [2] $(*)$ & 30 & $90: 10$ & $8.1 \%$ & - & $7.5 \%$ & - & - \\
\hline Yin-2014 [46] $(* *)$ & 25 & $90.5: 9.5$ & $12.8 \%$ & $11.3 \%$ & $9.3 \%$ & $7.8 \%$ & 788 \\
\hline This work [IMP] $\left({ }^{*}\right)$ & 23 & $80: 20$ & $11.3 \%$ & $8.0 \%$ & $6.1 \%$ & $5.9 \%$ & 527 \\
\hline This work [SC-STS] $(*)$ & 23 & $80: 20$ & $11.7 \%$ & $9.8 \%$ & $8.5 \%$ & $8.1 \%$ & 723 \\
\hline This work [SC-STS-E] $\left({ }^{*}\right)$ & 23 & $80: 20$ & $12.7 \%$ & $11.5 \%$ & $9.0 \%$ & $8.8 \%$ & 786 \\
\hline
\end{tabular}

(*) 5 wt. \% Mo

$\left({ }^{* *}\right)$ MCM-22 as support

Kosinov et al. [36] presented a strategy for the cyclic regeneration of Mo/ZSM-5 catalysts at MDA temperatures $\left(700^{\circ} \mathrm{C}\right)$. These authors were able to recover the initial activity of catalytic samples with low metal loading (<3 wt. \% Mo) for, at least, 7 consecutive regeneration cycles. Kosinov et al. [47] used periodic oxygen pulses in the methane feed in order to extend the aromatics production stability without regeneration. Rahman et al. [18] found that the presence of molybdenum carbide species prepared ex-situ enhances both methane conversion and benzene selectivity. Its effect on the aromatics yield became more noticeable in the samples containing 10 
- $12 \%$ Mo loading. Xu et al. [48] implemented a periodic $\mathrm{CH}_{4}-\mathrm{H}_{2}$ switching mode to extend the catalyst lifetime working at high temperatures and spatial velocities with Fe-promoted Mo/ZSM-5 samples.

Table 3. Literature review of long-term MDA performance ( $>5 \mathrm{~h}$ ) using Mo/zeolite-based catalysts promoted by additional features (doping metals, secondary gas co-feeding, support modifications, etc.)

\begin{tabular}{|c|c|c|c|c|c|c|c|c|}
\hline & $T$ & GHSV & & & $\%$ & & $\mathbf{x}_{\mathrm{CH} 4}$ & \\
\hline & $\left({ }^{\circ} \mathrm{C}\right)$ & $\left(\mathrm{mL} / \mathrm{g}_{\mathrm{cat}} \mathrm{h}\right)$ & $\mathrm{CH}_{4}: \mathrm{N}_{2}$ & $\%$ Mo & (Metal) & Zeolite (Si/Al) & (5h) & $\mathrm{Y}_{\mathrm{C6+}}(5 \mathrm{~h})$ \\
\hline Kosinov-2017 [36] & 700 & 6000 & $95 / 5$ & 5.5 & - & ZSM-5 (30) & - & $9.1 \%$ \\
\hline Kosinov-2016 [47] & 700 & 1680 & $100 / 0$ & 5 & - & ZSM-5 (13) & - & $8.8 \%$ \\
\hline Rahman-2018 [18] & 700 & 1550 & $100 / 0$ & 6 & - & ZSM-5 (30) & $8.6 \%$ & $6.4 \%^{b}$ \\
\hline Xu-2014 [48] & 800 & 10000 & $100 / 0$ & 5 & $0.5(\mathrm{Fe})$ & TNU-9 (20) & 15.9 & $11.1 \%$ \\
\hline Hu-2015 [49] & 700 & 1500 & $92.5 / 7.5$ & 6 & - & ZSM-5 (25) & $13.2 \%$ & $8.9 \%$ \\
\hline Sridhar-2018 [50] & 700 & 1500 & $91 / 9$ & 6 & $0.2 \%(\mathrm{Fe})$ & ZSM-5 (15) & - & $6.9 \%^{b}$ \\
\hline Liu-2011 [51] & 700 & 1500 & $92.5 / 7.5$ & 6 & - & TNU-9 (50) & $9.3 \%$ & $5.4 \%$ \\
\hline Martinez-2011 [52] & 700 & 1500 & $90 / 10$ & 3 & - & ZSM-5 (26) & $3.5 \%$ & $2.9 \%$ \\
\hline Abdelsayed-2015 [53] & 700 & 3000 & $90 / 10$ & 4 & $0.3(\mathrm{Fe})$ & ZSM-5 (55) & $5.0 \%$ & $4.3 \%$ \\
\hline Liu-2012 [54] & 700 & 1500 & $92.5 / 7.5$ & 5 & - & ZSM-5 (33) & $9.2 \%$ & $5.4 \%$ \\
\hline Tempelman-2016 [55] & 700 & 1800 & $95 / 5$ & 6 & - & MCM-22 (16) & $8.2 \%$ & $4.6 \%$ \\
\hline Sun-2015 [56] & 760 & 1500 & $90 / 10$ & 5.5 & - & ZSM-5 (20) & $12.6 \%$ & $8.4 \%^{b}$ \\
\hline Wang-2018 [57] & 700 & 1500 & $90 / 10$ & 6 & - & ZSM-5 (31) & $17.1 \%$ & $13.2 \%^{\mathrm{c}}$ \\
\hline Zhang-2016 [58] & 700 & 1440 & $98 / 2$ & 2 & $3(\ln )$ & ZSM-5 (23) & $5.6 \%$ & $4.7 \%$ \\
\hline $\operatorname{Ma-2005}[59]^{a}$ & 750 & 3000 & $100 / 0$ & 6 & - & ZSM-5 (-) & - & $4.4 \%^{b}$ \\
\hline Lim-2018 [60] & 680 & 3000 & $90 / 10$ & 5 & - & MCM-22 (21) & $4.3 \%$ & $3.2 \%$ \\
\hline Kosinov-2019 $[14]^{d}$ & 700 & 3000 & $100 / 0$ & 2 & - & ZSM-5 (13) & $6.6 \%$ & $4.0 \%$ \\
\hline Sun-2017 [61] & 700 & 1650 & $100 / 10$ & 5 & $1(\mathrm{Fe})$ & ZSM-5 (30) & $13.8 \%$ & $6.1 \%$ \\
\hline \multicolumn{9}{|c|}{ Honeycomb catalyst, pressurized reaction line (3 bar) } \\
\hline \multicolumn{9}{|l|}{ Benzene yield } \\
\hline
\end{tabular}

Hu et al. [62] used in-house synthesized $\mathrm{MoO}_{3}$ particles as metal precursor to promote aromatics selectivity. Sridhar et al. [50] enhanced benzene yield and catalytic stability 
using both precarburization strategies (i.e. feeding $\mathrm{CH}_{4} / \mathrm{H}_{2}$ while heating the sample) and promoting the catalyst adding small amounts of Fe. Liu et al. [51] found that the use of TNU- 9 as catalyst support instead of ZSM-5 promoted both methane conversion and the benzene-to-naphthalene production rate. Martinez et al. [52] modified the ZSM-5 support including intracrystalline mesopores. These variations led to a slight promotion of methane conversion and limitation of coke production after 8 hours on stream. Abdelsayed et al. [53] also found that the addition of small amounts of Fe on the Mo-based catalyst promotes MDA reaction. In contrast, the addition of $\mathrm{Zn}$ did not show any positive effect on the process. In agreement with Martinez et al. [52], Liu et al. [54] found a slight increase in the aromatics production using in-house synthesized mesoporous ZSM-5. Tempelman et al. [55] described the one-pot synthesis of nanocrystalline MCM-22 and its use as catalyst support for MDA. The increased accessibility of the internal acid sites in the Mo-loaded hierarchical MCM-22 improved benzene selectivity during MDA. Sun et al. [56] used a periodic $\mathrm{CH}_{4}-\mathrm{H}_{2}$ switch strategy similar to that reported by $\mathrm{Xu}$ et al. [48] keeping a nearly constant methane conversion (13 $16 \%)$ and outstanding aromatics yield (>10\%) for 1000 hours on stream, which represents the longest reported TOS in literature for the MDA process. Wang et al. [57] synthesized an unconventional hollow ZSM-5 zeolite capsules with large cavity in core and aggregated mesopores in shell that significantly outperformed the conventional ZSM-5 microporous support in terms of methane conversion and aromatics selectivity. Zhang et al. [58] found that the addition of a significant amount of indium ( $3 \mathrm{wt} . \%$ ) to a $2 \% \mathrm{Mo} / \mathrm{ZSM}-5$ catalyst decreased coke formation during MDA. Ma et al. [59] enhanced aromatics production stability by co-feeding small amounts of water or $\mathrm{H}_{2}$ /water mixtures with methane. Lim et al. [60] employed MCM-22 as support and 
studied the effect of the acidity (Si/Al ratio) on the catalyst performance. Finally, Sun et al. [61] reveals that both methane conversion and overall stability was substantially promoted by adding $1 \mathrm{wt}$. \% Fe nanoparticles to the standard 5\%Mo/ZSM-5.

Summarizing the previous literature results, only the catalytic performance reported by Sun et al. [56] and Xu et al. [48] (based on the periodic $\mathrm{CH}_{4}-\mathrm{H}_{2}$ switching) and that reported by Wang et al. [57] (based on the use of hollow ZSM-5 capsules) match the results obtained with the SC-STS-E sample in terms of catalytic stability and aromatics yield. On this regard, the potential advantages of the suggested SC-STS-E method with respect to the synthesis procedures described above are two-fold: i) SC-STS is a continuous synthesis procedure and commercially available ZSM- 5 zeolites can be used as catalyst support, i.e. hierarchical zeolites do not need to be fabricated on purpose; this would facilitate the potential catalyst synthesis scaling; ii) The outstanding stability of the SC-STS-E hydrocarbon productivity was obtained without co-feeding any stabilizing gas (e.g. $\mathrm{H}_{2}$ as reducing agent).

\section{CONCLUSIONS}

A continuous solvothermal synthesis method under supercritical conditions and reducing atmosphere (SC-STS-E) has been developed to synthesize Mo/ZSM-5 based catalysts consisting of well dispersed $\mathrm{MoO}_{\mathrm{x}}$ species within the zeolite pores for their use in methane dehydroaromatization. Characterization results confirm that this technique allows the loading of up to 4.7 wt. \% Mo content at the ZSM-5 pores without apparent aggregation of Mo entities at the external surface of the zeolite. The resulting metal dispersion and catalytic stability outperformed that provided by the traditional Mo/ZSM-5 catalyst prepared by impregnation. Methane conversion and 
hydrocarbon productivity after 15 hours on stream increased by $45 \%$ and $36 \%$, respectively, compared to the impregnated catalyst. The sample SC-STS-E provided long-term reactivity and stability due to the delayed formation of hard coke species with detrimental effect on the activity of the Mo active sites. Based on the very promising results and excellent Mo dispersion, this work opens a possibility to extend the proposed synthesis method to other heterogeneous catalytic systems that require high metal dispersion.

\section{CONFLICTS OF INTEREST}

There are no conflicts to declare.

\section{ACKNOWLEDGEMENTS}

Financial support from the European Union's Horizon 2020 Research and Innovation Programme (ADREM project - Grant Agreement No. 680777) is gratefully acknowledged. The microscopy measurements were conducted at the Laboratorio de Microscopias Avanzadas, Instituto de Nanociencia de Aragon, Universidad de Zaragoza, Spain. The synthesis of materials has been performed by the Platform of Production of Biomaterials and Nanoparticles of the NANOBIOSIS ICTS, more specifically by the Nanoparticle Synthesis Unit of the CIBER in BioEngineering, Biomaterials \& Nanomedicine (CIBER-BBN). The authors thank Dr. Patricia Concepción (Instituto de Tecnología Química, Valencia, Spain) for the characterization of the samples acidity by FTIR spectroscopy of CO adsorption.

\section{REFERENCES}


1. W. Taifan, J. Baltrusaitis, $\mathrm{CH}_{4}$ conversion to value added products: Potential, limitations and extensions of a single step heterogeneous catalysis, Appl. Catal. B: Environ. 198 (2016) 525547.

2. S.J. Han, S.K. Kim, A. Hwang, S. Kim, D. Hong, G. Kwak, K. Jun, Y.T. Kim, Non-oxidative dehydroaromatization of methane over Mo/H-ZSM-5 catalysts: A detailed analysis of the reaction-regeneration cycle, Appl. Catal. B: Environ. 241 (2019) 305-318.

3. C.H.L. Tempelman, E.J.M. Hensen, On the deactivation of Mo/HZSM-5 in the methane dehydroaromatization reaction, Appl. Catal. B: Environ. 176 (2015) 731-739.

4. BP, BP Statistical review of world energy 2017 (2016).

5. T.S. Collet, A.H. Johnson, C.C. Knapp, R. Boswell, Natural gas hydrates: a review, Natural Gas Hydrates - Energy Resource Potential and Associated Geological Hazards. AAPG Memoir 89 (2009) 146-219.

6. A.I. Olivos-Suarez, A. Szecsenyi, E.J.M. Hensen, J. Ruiz-Martinez, E.A. Pidko, J. Gascon, Strategies for the direct catalytic valorization of methane using heterogeneous catalysis: Challenges and Opportunities, ACS Catal. 6 (2016) 2965-2981.

7. R. Horn, R. Schloegl, Methane activation by heterogeneous catalysis, Catal. Lett. 145 (2015) 23-39.

8. J.J. Spivey, G. Hutchings, Catalytic aromatization of methane, Chem. Soc. Rev. 43 (2014) $792-$ 803.

9. Z.R. Ismagilov, E.V. Matus, L.T. Tsikoza, Direct conversion of methane on Mo/ZSM-5 catalysts to produce benzene and hydrogen: achievements and perspectives, Energ. Environ. Sci. 1 (2008) 526-541.

10. K. Sun, D.M. Ginosar, T. He, Y. Zhang, M. Fan, R. Chen, Progress in nonoxidative dehydroaromatization of methane in the last 6 years, Ind. Eng. Chem. Res. 57 (2018) 17681789.

11. S. Ma, X. Guo, L. Zhao, S. Scott, X. Bao, Recent progress in methane dehydroaromatization: From laboratory curiosities to promising technology, J. Energ. Chem. 22 (2013) 1-20.

12. N. Kosinov, F.J.A.G. Coumans, E.A. Uslamin, A.S.G. Wijpkema, B. Mezari, E.J.M. Hensen, Methane dehydroaromatization by Mo/HZSM-5: mono- or bifunctional catalysis?, ACS Catal. 7 (2017) 520-529.

13. Y. Xu, X. Bao, L. Lin, Direct conversion of methane under nonoxidative conditions, J. Catal. 216 (2003) 386-395.

14. N. Kosinov, E.A. Uslamin, L. Meng, A. Parastaev, Y. Liu, E.J.M. Hensen, Reversible nature of coke formation on Mo/ZSM-5 methane dehydroaromatization catalysts, Angew. Chem. -Int. Edit. 58 (2019) 7068-7072. 
15. C. Karakaya, S.H. Morejudo, H. Zhu, R.J. Kee, Catalytic Chemistry for methane dehydroaromatization (MDA) on a bifunctional Mo/HZSM-5 catalyst in a packed bed, Ind. Eng. Chem. Res. 55 (2016) 9895-9906.

16. C.H.L. Tempelman, X. Zhu, E.J.M. Hensen, Activation of Mo/HZSM-5 for methane aromatization, Chin. J. Catal. 36 (2015) 829-837.

17. V. Ha, L. Tiep, P. Meriaudeau, C. Naccache, Aromatization of methane over zeolite supported molybdenum: active sites and reaction mechanism, J. Molec. Catal. A-Chem. 181 (2002) 283-290.

18. M. Rahman, A. Sridhar, S.J. Khatib, Impact of the presence of Mo carbide species prepared ex situ in Mo/HZSM-5 on the catalytic properties in methane aromatization, Appl. Catal. A: Gen. 558 (2018) 67-80.

19. D. Ma, Y. Shu, M. Cheng, Y. Xu, X. Bao, On the induction period of methane aromatization over Mo-based catalysts, J. Catal. 194 (2000) 105-114.

20. P. Schwach, X. Pan, X. Bao, Direct Conversion of methane to value-added chemicals over heterogeneous catalysts: challenges and prospects, Chem. Rev. 117 (2017) 8497-8520.

21. V. Ha, L. Tiep, P. Meriaudeau, C. Naccache, Aromatization of methane over zeolite supported molybdenum: active sites and reaction mechanism, J. Molec. Catal. A-Chem. 181 (2002) 283-290.

22. I. Vollmer, G. Li, I. Yarulina, N. Kosinov, E.J. Hensen, K. Houben, D. Mance, M. Baldus, J. Gascon, F. Kapteijn, Relevance of the Mo-precursor state in H-ZSM-5 for methane dehydroaromatization, Catal.Sci. Technol. 8 (2018) 916-922.

23. K.S. Wong, J.W. Thybaut, E. Tangstad, M.W. Stocker, G.B. Marin, Methane aromatisation based upon elementary steps: kinetic and catalyst descriptors, Micro. Meso. Mat. 164 (2012) 302-312.

24. C. Kallesøe, H.F. Clausen, L.H. Christensen, Method of preparing a catalyst structure, EP Patent App. EP 3092067 A1 (2016).

25. C. Kallesøe, H.F. Clausen, L.H. Christensen, T. Lund-Olesen, M.A. Hasen Mamakhel, B.B. Iversen, J. Becker-Christensen, D.F. Aarup, J. Hales, Method of preparing a catalytic structure, CA Patent App. CA 2874888 A1 (2014).

26. M. Bondesgaard, J. Becker, J. Xavier, H. Hellstern, A. Mamakhel, B.B. Iversen, Guide to byproducts formed in organic solvents under solvothermal conditions, J. Supercrit. Fluids 113 (2016) 166-197.

27. L. Wang, L. Tao, M. Xie, G. Xu, J. Huang, Y. Xu, Dehydrogenation and aromatization of methane under nonoxidizing conditions, Catal. Lett. 21 (1993) 35-41.

28. J. Rouquerol, P. Llewellyn, F. Rouquerol, Is the BET equation applicable to microporous adsorbents), Stu. Surf. Sci. Catal. 160 (2006) 49-56. 
29. I. Julian, J.L. Hueso, N. Lara, A. Sole-Daura, J.M. Poblet, S. Mitchell, R. Mallada, J. Santamaria, Polyoxometalates as alternative Mo precursors for methane dehydroaromatization on Mo/ZSM-5 and Mo/MCM-22 catalysts, Catal. Sci. Technol. (2019) In press.

30. I. Julian, H. Ramirez, J.L. Hueso, R. Mallada, J. Santamaria, Non-oxidative methane conversion in microwave-assisted structured reactors, Chem. Eng. J. (2018) In press, DOI: 10.1016/j.cej.2018.08.150.

31. L. Kustov, V. Kazansky, S. Beran, L. Kubelkova, P. Jiru, Adsorption of Carbon-Monoxide on Zsm-5 Zeolites - Infrared Spectroscopic Study and Quantum-Chemical Calculations, J. Phys. Chem. 91 (1987) 5247-5251.

32. Y. Song, C. Sun, W. Shen, L. Lin, Hydrothermal post-synthesis of HZSM-5 zeolite to enhance the coke-resistance of Mo/HZSM-5 catalyst for methane dehydroaromatization reaction: Reconstruction of pore structure and modification of acidity, Appl. Catal. A: Gen. 317 (2007) 266-274.

33. D. Wang, J.H. Lunsford, M.P. Rosynek, Characterization of a Mo/ZSM-5 catalyst for the conversion of methane to benzene, J. Catal. 169 (1997) 347-358.

34. J.L. Hueso, J.P. Espinos, A. Caballero, J. Cotrino, A.R. Gonzalez-Elipe, XPS investigation of the reaction of carbon with $\mathrm{NO}, \mathrm{O}_{2}, \mathrm{~N}_{2}$ and $\mathrm{H}_{2} \mathrm{O}$ plasmas, Carbon 45 (2007) 89-96.

35. Á Ibarra, A. Veloso, J. Bilbao, J.M. Arandes, P. Castaño, Dual coke deactivation pathways during the catalytic cracking of raw bio-oil and vacuum gasoil in FCC conditions, Appl. Catal. B: Environ. 182 (2016) 336-346.

36. N. Kosinov, F.J.A.G. Coumans, G. Li, E. Uslamin, B. Mezari, A.S.G. Wijpkema, E.A. Pidko, E.J.M. Hensen, Stable Mo/HZSM-5 methane dehydroaromatization catalysts optimized for high-temperature calcination-regeneration, J. Catal. 346 (2017) 125-133.

37. D. Ma, Y. Shu, X. Han, X. Liu, Y. Xu, X. Bao, Mo/HMCM-22 catalysts for methane dehydroaromatization: A multinuclear MAS NMR study, J. Phys. Chem. B 105 (2001) 17861793.

38. B. Wang, S. Albarracín-Suazo, Y. Pagán-Torres, E. Nikolla, Advances in methane conversion processes, Catal. Today 285 (2017) 147-158.

39. N. Kosinov, A.S.G. Wijpkema, E. Uslamin, R. Rohling, F.J.A.G. Coumans, B. Mezari, A. Parastaev, A.S. Poryvaev, M.V. Fedin, E.A. Pidko, E.J.M. Hensen, Confined Carbon Mediating Dehydroaromatization of Methane over Mo/ZSM-5, Angew. Chem.-Int. Ed. 57 (2018) 10161020.

40. H. Liu, C. Zhou, Y. Zhang, Q. Kan, Facile preparation of hierarchically porous IM-5 zeolite with enhanced catalytic performance in methane aromatization, J. Fuel Chem. Technol. 45 (2017) 1074-1081.

41. Y. Liu, M. Zhao, L. Cheng, J. Yang, L. Liu, J. Wang, D. Yin, J. Lu, Y. Zhang, Facile synthesis and its high catalytic performance of hierarchical ZSM-5 zeolite from economical bulk silicon oxides, Micro. Meso. Mat. 260 (2018) 116-124. 
42. P. Tan, The catalytic performance of Mo-impregnated $\mathrm{HZSM}-5$ zeolite in $\mathrm{CH}_{4}$ aromatization: Strong influence of Mo loading and pretreatment conditions, Catal. Comm. 103 (2018) 101104.

43. Y. Xu, J. Lu, J. Wang, Z. Zhang, Mo-based zeolite catalysts and oxygen-free methane aromatization, Prog. Chem. 23 (2011) 90-106.

44. H. Liu, X. Bao, Y. Xu, Methane dehydroaromatization under nonoxidative conditions over Mo/HZSM-5 catalysts: Identification and preparation of the Mo active species, J. Catal. 239 (2006) 441-450.

45. A. Martinez, E. Penis, Non-oxidative methane dehydroaromatization on Mo/HZSM-5 catalysts: Tuning the acidic and catalytic properties through partial exchange of zeolite protons with alkali and alkaline-earth cations, Appl. Catal. A: Gen. 515 (2016) 32-44.

46. X. Yin, N. Chu, J. Yang, J. Wang, Z. Li, Synthesis of the nanosized MCM-22 zeolite and its catalytic performance in methane dehydro-aromatization reaction, Catal. Comm. 43 (2014) 218-222.

47. N. Kosinov, F.J.A.G. Coumans, E. Uslamin, F. Kapteijn, E.J.M. Hensen, Selective Coke Combustion by Oxygen Pulsing During Mo/ZSM-5-Catalyzed Methane Dehydroaromatization, Angew. Chem.-Int. Ed. 55 (2016) 15086-15090.

48. Y. Xu, Y. Song, Y. Suzuki, Z. Zhang, Mechanism of Fe additive improving the activity stability of microzeolite-based Mo/HZSM-5 catalyst in non-oxidative methane dehydroaromatization at $1073 \mathrm{~K}$ under periodic $\mathrm{CH} 4-\mathrm{H}-2$ switching modes, Catal. Sci. Technol. 4 (2014) 3644-3656.

49. J. Hu, S. Wu, Y. Ma, X. Yang, Z. Li, H. Liu, Q. Huo, J. Guan, Q. Kan, Effect of the particle size of $\mathrm{MoO}_{3}$ on the catalytic activity of Mo/ZSM-5 in methane non-oxidative aromatization, New J. Chem. 39 (2015) 5459-5469.

50. A. Sridhar, M. Rahman, S.J. Khatib, Enhancement of molybdenum/ZSM-5 catalysts in methane aromatization by the addition of iron promoters and by reduction/carburization pretreatment, Chemcatchem 10 (2018) 2571-2583.

51. H. Liu, S. Yang, S. Wu, F. Shang, X. Yu, C. Xu, J. Guan, Q. Kan, Synthesis of Mo/TNU-9 (TNU-9 Taejon National University No. 9) catalyst and its catalytic performance in methane nonoxidative aromatization, Energy 36 (2011) 1582-1589.

52. A. Martinez, E. Peris, M. Derewinski, A. Burkat-Dulak, Improvement of catalyst stability during methane dehydroaromatization (MDA) on Mo/HZSM-5 comprising intracrystalline mesopores, Catal. Today 169 (2011) 75-84.

53. V. Abdelsayed, D. Shekhawat, M.W. Smith, Effect of Fe and Zn promoters on Mo/HZSM-5 catalyst for methane dehydroaromatization, Fuel 139 (2015) 401-410.

54. H. Liu, S. Yang, J. Hu, F. Shang, Z. Li, C. Xu, J. Guan, Q. Kan, A comparison study of mesoporous Mo/H-ZSM-5 and catalysts in methane non-oxidative aromatization, Fuel Proc. Technol. 96 (2012) 195-202. 
55. C.H.L. Tempelman, M. Teresa Portilla, M.E. Martinez-Armero, B. Mezari, N.G.R. de Caluwe, C. Martinez, E.J.M. Hensen, One-pot synthesis of nano-crystalline MCM-22, Micro. Meso. Mat. 220 (2016) 28-38.

56. C. Sun, G. Fang, X. Guo, Y. Hu, S. Ma, T. Yang, J. Han, H. Ma, D. Tan, X. Bao, Methane dehydroaromatization with periodic $\mathrm{CH}_{4}-\mathrm{H}_{2}$ switch: A promising process for aromatics and hydrogen, J. Energ. Chem. 24 (2015) 257-263.

57. K. Wang, X. Huang, D. Li, Hollow ZSM-5 zeolite grass ball catalyst in methane dehydroaromatization: One-step synthesis and the exceptional catalytic performance, Appl. Catal. A: Gen. 556 (2018) 10-19.

58. Y. Zhang, M. Kidder, R.E. Ruther, J. Nanda, G.S. Foo, Z. Wu, C.K. Narula, Promotional Effects of In on Non-Oxidative Methane Transformation Over Mo-ZSM-5, Catal. Lett. 146 (2016) 19031909.

59. H. Ma, R. Kojima, S. Kikuchi, M. Ichikawa, Effective coke removal in methane to benzene (MTB) reaction on Mo/HZSM-5 catalyst by $\mathrm{H}-2$ and $\mathrm{H} 2 \mathrm{O}$ co-addition to methane, Catal. Lett. 104 (2005) 63-66.

60. T.H. Lim, K. Nam, I.K. Song, K. Lee, D.H. Kim, Effect of Si/Al2 ratios in Mo/H-MCM-22 on methane dehydroaromatization, Appl. Catal. A: Gen. 552 (2018) 11-20.

61. K. Sun, W. Gong, K. Gasem, H. Adidharma, M. Fan, R. Chen, Catalytic Methane Dehydroaromatization with Stable Nano Fe Doped on Mo/HZSM-5 Synthesized with a Simple and Environmentally Friendly Method and Clarification of a Perplexing Catalysis Mechanism Dilemma in This Field for a Period of Time, Ind. Eng. Chem. Res. 56 (2017) 11398-11412.

62. J. Hu, S. Wu, Y. Ma, X. Yang, Z. Li, H. Liu, Q. Huo, J. Guan, Q. Kan, Effect of the particle size of $\mathrm{MoO} 3$ on the catalytic activity of Mo/ZSM-5 in methane non-oxidative aromatization, New J. Chem. 39 (2015) 5459-5469. 